\title{
CXCR4 over-expression and survival in cancer: A system review and meta-analysis
}

\author{
Hongli Zhao ${ }^{1, *}$, Liyuan Guo ${ }^{2,}{ }^{*}$, Hong Zhao ${ }^{1,}{ }^{*}$, Jiaxin Zhao ${ }^{3}$, Hao Weng ${ }^{4}$ and Bin Zhao ${ }^{5}$ \\ ${ }^{1}$ Department of Medical Oncology, The Third Affiliated Hospital of Harbin Medical University, Harbin, China \\ 2 Department of Gynecological Oncology, The Third Affiliated Hospital of Harbin Medical University, Harbin, China \\ ${ }^{3}$ Department of Neurosurgery, The Fourth Affiliated Hospital of Harbin Medical University, Harbin, China \\ ${ }^{4}$ Shanghai Jiaotong University Affiliated Sixth People's Hospital South Campus, Shanghai, China \\ ${ }^{5}$ Harbin Medical University, Daqing Campus, China \\ * Authors contributed equally to this work and were co-first authors \\ Correspondence to: Bin Zhao, email: bin.science@gmail.com \\ Keywords: CXCR4, cancer, survival, prognostic biomarker, meta-analysis \\ Received: November 23, $2014 \quad$ Accepted: December 28, $2014 \quad$ Published: December 31, 2014
}

This is an open-access article distributed under the terms of the Creative Commons Attribution License, which permits unrestricted use, distribution, and reproduction in any medium, provided the original author and source are credited.

\section{ABSTRACT}

C-X-C chemokine receptor 4 (CXCR4) is frequently over-expressed in various types of cancer; many agents against CXCR4 are in clinical development currently despite variable data for the prognostic impact of CXCR4 expression. Here eighty-five studies with a total of 11,032 subjects were included to explore the association between CXCR4 and progression-free survival (PFS) or overall survival (OS) in subjects with cancer. Pooled analysis shows that CXCR4 over-expression is significantly associated with poorer PFS (HR 2.04; 95\% CI, 1.72-2.42) and OS (HR=1.94; 95\% CI, 1.712.20) irrespective of cancer types. Subgroup analysis indicates significant association between CXCR4 and shorter PFS in hematological malignancy, breast cancer, colorectal cancer, esophageal cancer, renal cancer, gynecologic cancer, pancreatic cancer and liver cancer; the prognostic effects remained consistent across age, risk of bias, levels of adjustment, median follow-up period, geographical area, detection methods, publication year and size of studies. CXCR4 over-expression predicts unfavorable OS in hematological malignancy, breast cancer, colorectal cancer, esophageal cancer, head and neck cancer, renal cancer, lung cancer, gynecologic cancer, liver cancer, prostate cancer and gallbladder cancer; these effects were independence of age, levels of adjustment, publication year, detection methods and follow-up period. In conclusion, CXCR4 over-expression is associated with poor prognosis in cancer.

\section{INTRODUCTION}

Cancer is a major public health problem globally. It is estimated that 12.7 million cancer cases and 7.6 million cancer deaths occurred in 2008[1], and these numbers will continue to increase because of the aging and growth of the world population along with the overwhelming adoption of cancer-causing behaviors, like smoking, the consumption of high-fat diets and physical inactivity, in economically developing countries. Combination of surgery, radiotherapy and chemotherapy remains the standard treatment in most cancer cases; however, not all patients derive benefit from it. Therefore, it is of great clinical value to identify applicable prognostic biomarkers, not only improving poor prognosis but also providing novel therapeutic targets. In the past decade, growing appreciation of the role of microenvironment in driving cancer cell biology has improved the understanding of oncologic disease. C-X-C chemokine receptor 4 (CXCR4) is believed to be one key factor in the cross-talking between cancer cells and its microenvironment, what makes it a very promising prognostic biomarker and target for cancer therapy[2].

CXCR4, a G-protein coupled chemokine receptor encoded on chromosome 2[3], exerts its biological effect by binding stromal cell-derived factor 1 (SDF-1)[4]; 
recent evidence demonstrates ubiquitin, a small (76-amino acid) protein highly conserved among eukaryotic cells, is also a natural ligand of CXCR4[5]. The expression of CXCR4 is low or absent in many healthy tissues, but it is demonstrated that CXCR4 is highly expressed in various different tumor types and has been considered the most widely expressed chemokine receptor in cancer[6]. Additionally, over-expression of CXCR4 in cancer specimens is associated with chemotaxis, invasion, angiogenesis and proliferation independent of their specific histological findings[7]. The important roles of CXCR4 in multiple diseases have encouraged the development of clinically viable CXCR4 antagonists, and resulted in the US Food and Drug Administration (FDA) approval of the first CXCR4 antagonist, plerixafor for patients with non-Hodgkin's lymphoma and multiple myeloma[2].

Despite the clinical development of anti-CXCR4 therapies, the prognostic value of CXCR4 overexpression across different tumors still remains unclear. Many studies have provided an insignificant association between CXCR4 expression and clinical outcome [811]. An improved understanding of this issue could have important public health and clinical implication considering many tumors are still incurable. With recently accumulating evidence, our goal here, therefore, was to evaluate the association between CXCR4 over-expression and progression-free survival (PFS) and overall survival (OS) by conducting a meta-analysis among patients with different types of cancer, thereby allowing more rational development of therapeutic strategies against this receptor.

\section{RESULTS}

\section{Eligible studies}

The search strategy identified 3521 unique citations. After initial screening based on titles and abstracts, 3231 studies were excluded. The main reasons for exclusion were failure to examine disease prognosis or the studies were not original studies. Of the 290 articles remained for further evaluation, 205 were excluded in the subsequent detailed assessments for no related information regarding PFS and OS or insufficient data for quantitative analysis. The remaining 85 reports met our inclusion criteria and were included in this meta-analysis. A flow chart showing the study selection was presented in Figure 1.

\section{Study characteristics}

The characteristics of the selected 85 studies are presented in Supplement table 1-3. These papers were published between 2004 and 2014 and all studies used retrospective cohort designs. A total of 11,032 participants were analyzed for CXCR4 status and its relationship to disease prognosis, of which 5971 (54\%) were classified as CXCR4 over-expression. The average number of patients for these studies was 130, the average age was 58 years old and the mean follow-up was 53 months (Supplement table 1). The overall quality of the included studies was examined, $46(54 \%)$ studies were at low risk of bias, and the rest $39(46 \%)$ were at high risk of bias (Supplement table 2). Of all the 85 studies, 31 (36\%) had their outcomes adjust for covariates (Supplement table 3).Geographically, $18(22 \%)$ studies were conducted in the US and Canada, 25 (29\%) in Europe, 41 (48\%) in Asia, and 1(1\%) in South America. In these 85 studies, 65 (76\%) investigations detected the CXCR4 status by immunohistochemistry (IHC), $8(9 \%)$ studies used polymerase chain reaction (PCR), 7 (8\%) papers used western blot (WB), and the remaining $5(6 \%)$ researches detected CXCR4 by fluorescence-activated cell sorting (FACS). Among 65 studies using IHC, the cutoff values were determined by percentage of CXCR4-positive cells in 23 studies (27\%), by staining intensity scores in 20 studies (24\%), and the cutoff points of rest 22 papers $(26 \%)$ were based on both staining intensity score and percentage of CXCR4 positive cells.

Hematological malignancy ( 7 studies, 764 patients) [12-18], breast cancer (18 studies, 4125 patients)[10, 11, 19-34], colorectal cancer ( 7 studies, 515 patients)[35-41], esophageal cancer ( 7 studies, 886 patients)[42-48], gastric cancer (5 studies, 755 patients)[49-53], head and neck cancer ( 7 studies, 577 patients)[54-60], renal cancer (6 studies, 764 patients)[61-66], lung cancer (7 studies, 727 patients)[8, 67-72], melanoma (4 studies, 168 patients) [73-76], gynecologic cancer ( 8 studies, 826 patients) [9, 77-83], pancreatic cancer (2 studies, 320 patients)[84, 85], prostate cancer ( 2 studies, 109 patients)[86, 87], liver cancer ( 2 studies, 256 patients) [88, 89], sarcoma (2 studies, 168 patients) $[90,91]$ and gallbladder cancer (1 study, 72 patients)[92] were evaluated in current metaanalysis as shown in Table 1.

\section{CXCR4 and PFS}

Forty-seven studies, with a total of 5,592 patients, included data on progress free survival in 12 types of cancer $[8,10,12,14-27,31-33,35,38-40,43,45-48,53$, $56,63-66,70,73,75,77-80,82,83,85,88,89]$. Of all the participants, 2583 (46\%) were CXCR4 over-expression. Out of a maximum 9-point score in quality examination, 26 studies $(55 \%)$ were at low risk of bias, the rest 21 (45\%) were at high risk of bias. 20 studies (43\%) had PFS adjust to covariates. Geographically, 14 studies (30\%) including 1617 participants were conducted in the US and Canada, 15 studies (32\%) including 2176 participants in Europe, and 18 studies (38\%) including 1799 participants in Asia.

As shown in figure 2A, CXCR4 over-expression 
Table 1: Summary of 15 types of cancer studies included in current meta-analysis. IHC, immunohistochemistry; WB, western blot; RCR, polymerase chain reaction; FACS, fluorescence-activated cell sorting.

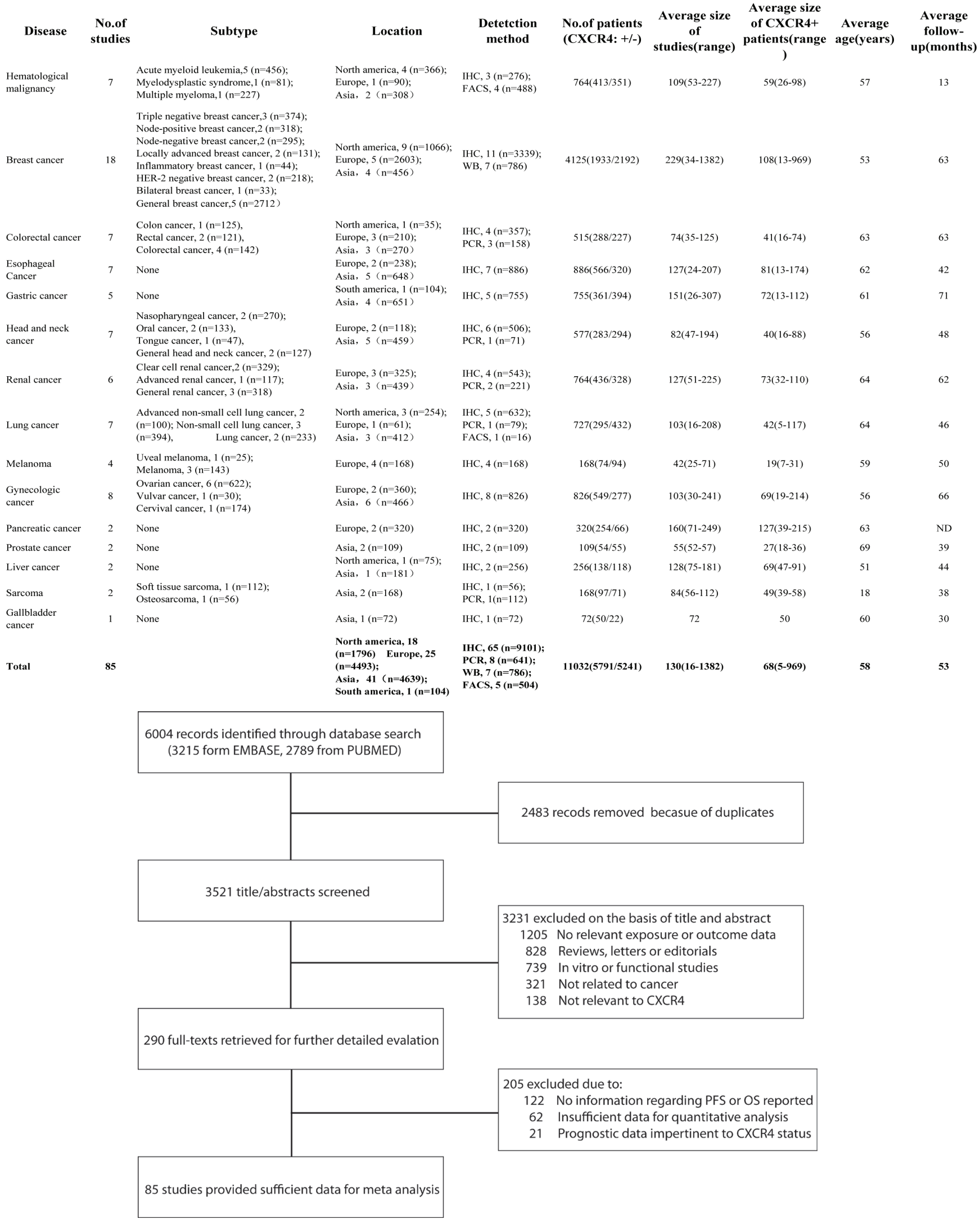

Figure 1: Using standardized protocol for a comprehensive search, a total of 85 studies were included for current meta-analysis. 
A

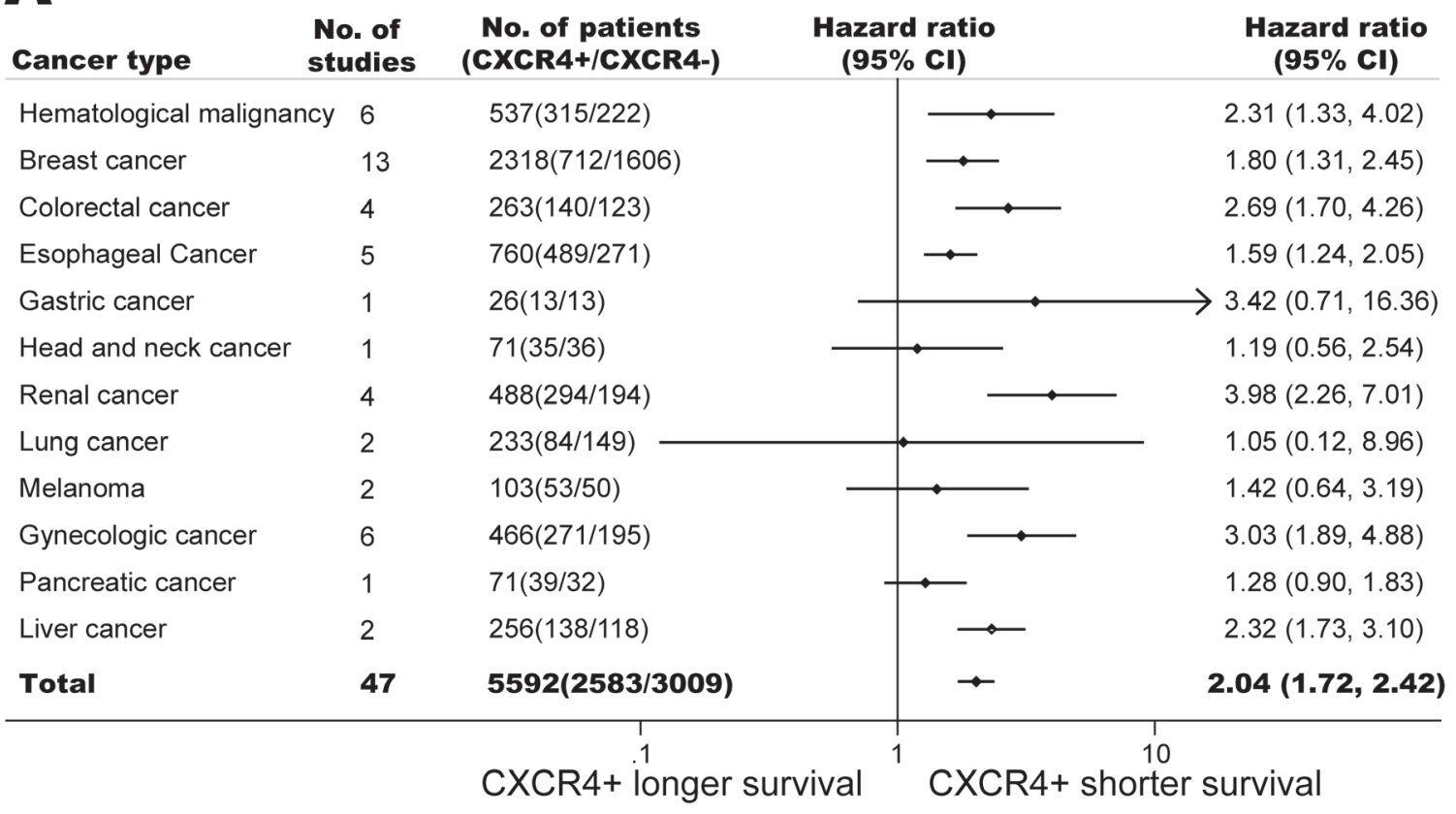

B

\begin{tabular}{|c|c|c|c|c|c|}
\hline Subgroups & $\begin{array}{l}\text { No. of } \\
\text { studies }\end{array}$ & $\begin{array}{l}\text { No. of patients } \\
\text { (CXCR4+/CXCR4-) }\end{array}$ & $\begin{array}{l}\text { Hazard ratio } \\
(95 \% \mathrm{CI})\end{array}$ & $\begin{array}{l}\text { Hazard ratio } \\
(95 \% \mathrm{CI})\end{array}$ & P-value \\
\hline \multicolumn{3}{|l|}{ Median age(year) } & & & \multirow[t]{2}{*}{0.29} \\
\hline $\begin{array}{l}<60 \\
>=60\end{array}$ & $\begin{array}{l}25 \\
15\end{array}$ & $\begin{array}{l}2708(1297 / 1411) \\
1624(922 / 702)\end{array}$ & & $\begin{array}{l}2.12(1.65,2.73) \\
1.74(1.33,2.28)\end{array}$ & \\
\hline $\begin{array}{l}\text { Size of studies } \\
<=100 \\
>100\end{array}$ & $\begin{array}{l}24 \\
23\end{array}$ & $\begin{array}{l}1573(830 / 743) \\
4019(1753 / 2266)\end{array}$ & & $\begin{array}{l}2.42(1.79,3.26) \\
1.80(1.53,2.11)\end{array}$ & 0.07 \\
\hline $\begin{array}{l}\text { Publication year } \\
<2010 \\
>=2010\end{array}$ & $\begin{array}{l}22 \\
25\end{array}$ & $\begin{array}{l}3263(1435 / 1828) \\
2329(1148 / 1181)\end{array}$ & & $\begin{array}{l}1.82(1.47,2.27) \\
2.30(1.73,3.05)\end{array}$ & 0.17 \\
\hline $\begin{array}{l}\text { Detection method } \\
\text { IHC } \\
\text { Other(FACS,PCR,WB) }\end{array}$ & $\begin{array}{l}32 \\
15\end{array}$ & $\begin{array}{l}4102(2016 / 2086) \\
1490(567 / 923)\end{array}$ & 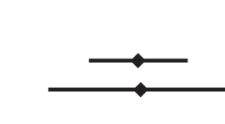 & $\begin{array}{l}2.04(1.69,2.46) \\
2.00(1.41,2.84)\end{array}$ & 0.96 \\
\hline $\begin{array}{l}\text { Geographical area } \\
\text { Europe } \\
\text { North America } \\
\text { Asia }\end{array}$ & $\begin{array}{l}15 \\
14 \\
18\end{array}$ & $\begin{array}{l}2176(892 / 1284) \\
1617(637 / 980) \\
1799(1054 / 745)\end{array}$ & & $\begin{array}{l}1.62(1.28,2.06) \\
2.41(1.82,3.19) \\
2.00(1.48,2.72)\end{array}$ & 0.11 \\
\hline $\begin{array}{l}\text { Median follow-up(mo } \\
<50 \\
>=50\end{array}$ & $\begin{array}{c}\text { onths) } \\
17 \\
13\end{array}$ & $\begin{array}{l}1886(976 / 910) \\
2089(663 / 1426)\end{array}$ & & $\begin{array}{l}2.28(1.76,2.95) \\
1.88(1.40,2.52)\end{array}$ & 0.33 \\
\hline $\begin{array}{l}\text { Adjustment for covar } \\
\text { Yes } \\
\text { No }\end{array}$ & $\begin{array}{l}\text { ariates } \\
20 \\
27\end{array}$ & $\begin{array}{l}1925(974 / 951) \\
3660(1602 / 2058)\end{array}$ & & $\begin{array}{l}2.18(1.63,2.92) \\
1.87(1.52,2.30)\end{array}$ & 0.40 \\
\hline $\begin{array}{l}\text { Newcastle-Ottawa sc } \\
\qquad 7 \\
>=7\end{array}$ & $\begin{array}{c}\text { scale sc } \\
21 \\
26\end{array}$ & $\begin{array}{l}\text { re } \\
\qquad 2994(1221 / 1773) \\
2598(1362 / 1236)\end{array}$ & $\rightarrow$ & $\begin{array}{l}1.81(1.41,2.32) \\
2.18(1.71,2.78)\end{array}$ & 0.30 \\
\hline
\end{tabular}

Figure 2: Association of CXCR4 over-expression and progress free survival (PFS). (A) Forest plot shows CXCR4 overexpression and PFS in 12 types of cancers. (B) CXCR4 over-expression is associated with worse PFS among cancer patients according to various characteristics.CI, confidence interval. Pooled estimates are based on random effects meta-analysis. Horizontal line represents $95 \% \mathrm{CI}$. 
was statistically associated with a poor PFS $(\mathrm{HR}=2.04$, 95\% CI, 1.72-2.42) when including all 47 studies; however, there was significant heterogeneity $\left(\mathrm{I}^{2}=71 \%\right.$, $\mathrm{p}<0.01)$. Meta-influence analysis did not suggest undue influence of any single study. Although five studies appeared to be outliers [8, 25, 63, 66, 77], we did not find clinical heterogeneity justifying their exclusion. Subsidiary analyses were carried out in the analysis of PFS (Figure 2B). In the eight predefined subgroup analyses, the prognostic effects were similar between the subgroups by line of risk of bias (Newcastle-Ottwa scale scores), levels

A

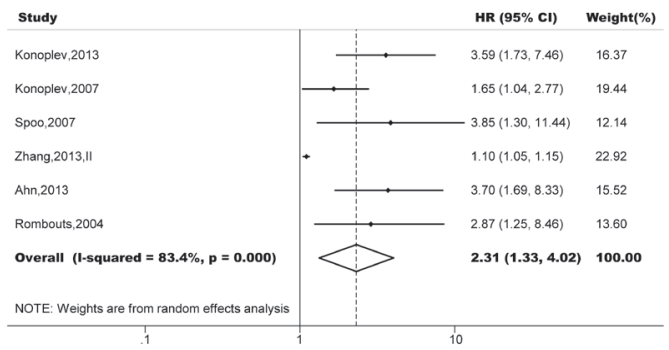

B

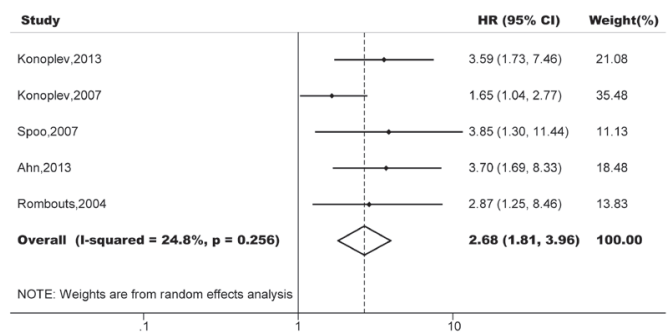

C

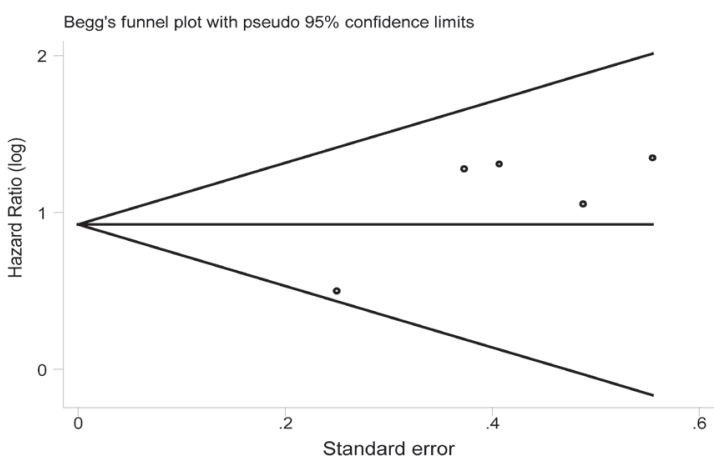

Figure 3: Forest plots show association between C-X-C chemokine receptor type 4 (CXCR4) over-expression and progression free survival (PFS) in hematological malignancy. Hazard ratios for each trial are represented by squares; the horizontal line crossing the square represents the $95 \%$ confidence interval. The diamonds represent the estimated pooled effect using the Mantel-Haenszel random-effect model. (A) Summary for all six trials, the estimates is 1.12(1.07-1.17) using fixed effects model. (B) Excluding the only study focused on myelodysplastic syndrome (Zhang, 2012) yield results without significant heterogeneity. The estimate is 2.62(1.823.48) using fixed effects model. (C) Funnel plots showing association of CXCR4 and PFS in hematological malignancy. Visual inspection of the Begg funnel plot did not identify substantial asymmetry. of adjustment, median follow-up period, geographical area, detection methods, publication year, size of studies and age. These results might indicate that the predictive ability of CXCR4 over-expression is independent of other clinical and pathological factors for the survival of cancer patients.

The pooled model showed a significantly shorter PFS with CXCR4 over-expression patients in hematological malignancy (6 studies, 537 patients, $\mathrm{HR}=2.31$, 95\% CI, 1.33-4.02, Figure 3) [12, 14-18], breast cancer (13 studies, 2318 patients, $\mathrm{HR}=1.80,95 \% \mathrm{CI}, 1.31$ -
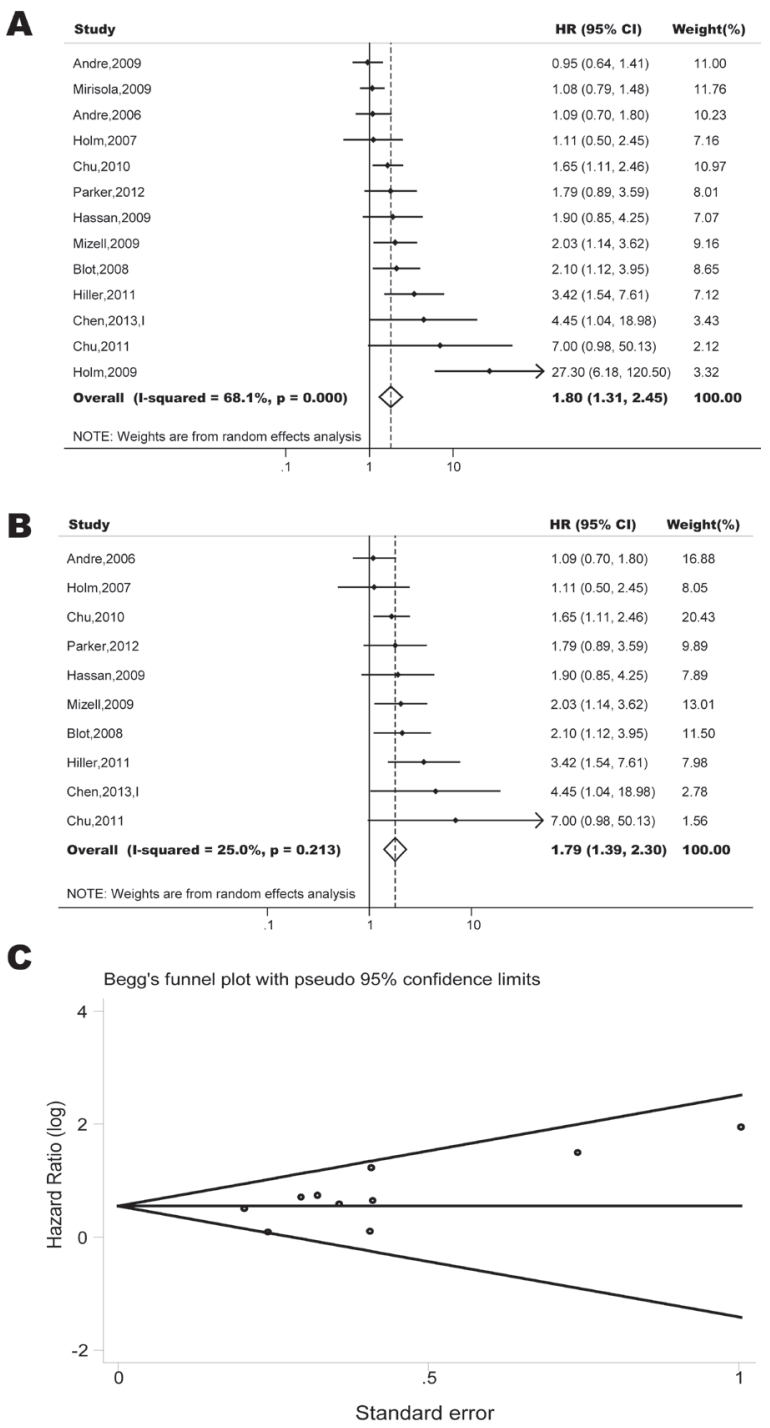

Figure 4: Forest plots show association between CXCR4 over-expression and PFS in breast cancer. (A) Summary for all thirteen trials, the estimates is $1.44(1.23-1.69)$ using fixed effects model. (B) Although three studies appeared to be outliers (Andre, 2009; Mirisola, 2009; Holm, 2009), we did not find clinical heterogeneity justifying their exclusion. Excluding three studies yield similar results but without significant heterogeneity. The estimate is $1.75(1.41-2.17)$ using fixed effects model. (C) Funnel plots showing association of CXCR4 and PFS in breast cancer. Visual inspection of the Begg funnel plot did not identify substantial asymmetry. 
A

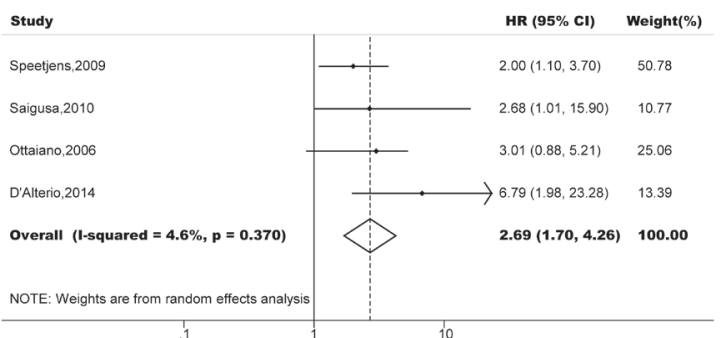

B

Begg's funnel plot with pseudo $95 \%$ confidence limits

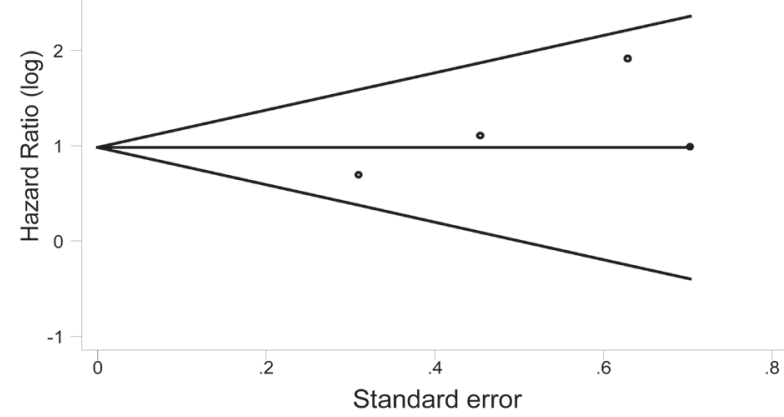

Figure 5: Forest plots show association between CXCR4 over-expression and PFS in colorectal cancer. (A) Summary for all four trials, the estimates is 2.67(1.71-4.13) using fixed effects model. (B) Funnel plots showing association of CXCR4 and PFS in colorectal cancer. Visual inspection of the Begg funnel plot did not identify substantial asymmetry.

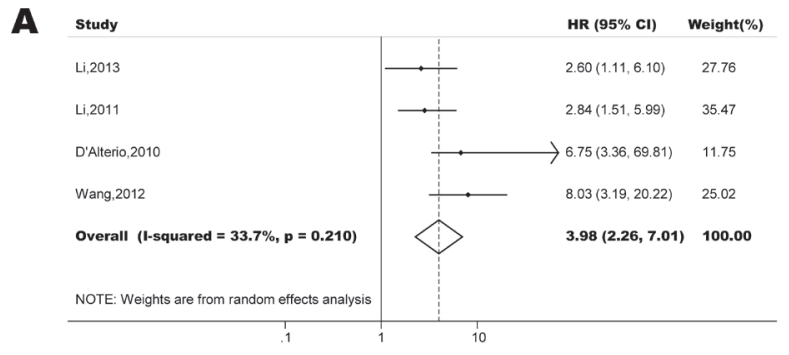

B

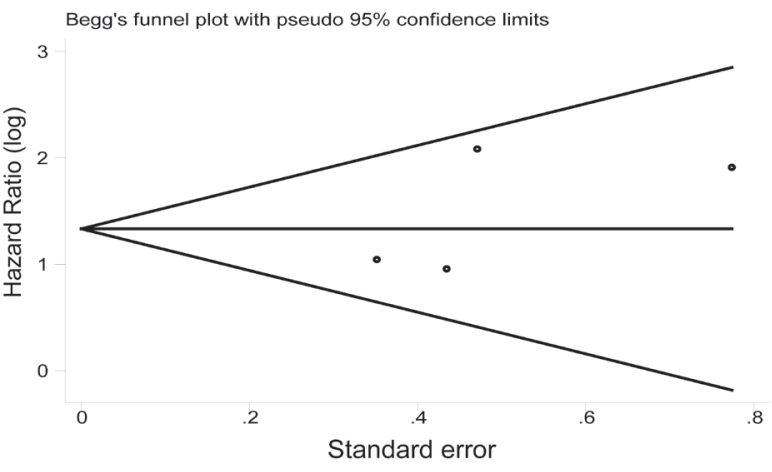

Figure 7: Forest plots show association between CXCR4 over-expression and PFS in renal cancer. (A) Summary for all four trials, the estimates is $3.80(2.44-5.91)$ using fixed effects model. (B) Funnel plots showing association of CXCR4 and PFS in renal cancer. Visual inspection of the Begg funnel plot did not identify substantial asymmetry.
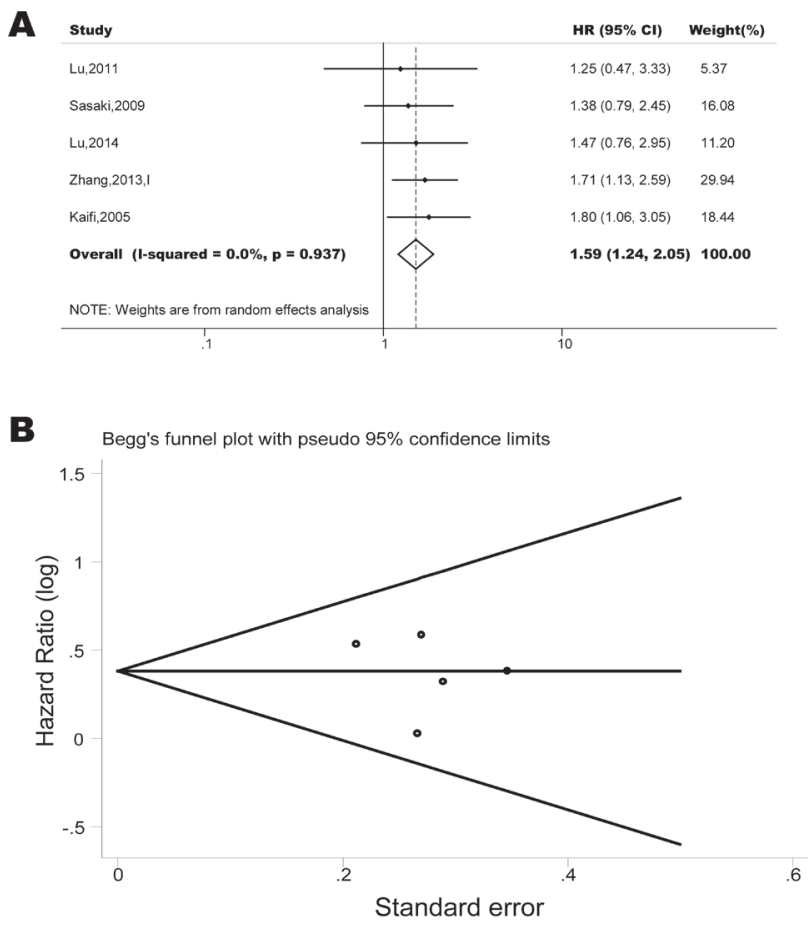

Figure 6: Forest plots show association between CXCR4 over-expression and PFS in esophageal cancer. (A) Summary for all six trials, the estimates is 1.59(1.24-2.05) using fixed effects model. (B) Funnel plots showing association of CXCR4 and PFS in esophageal cancer. Visual inspection of the Begg funnel plot did not identify substantial asymmetry.
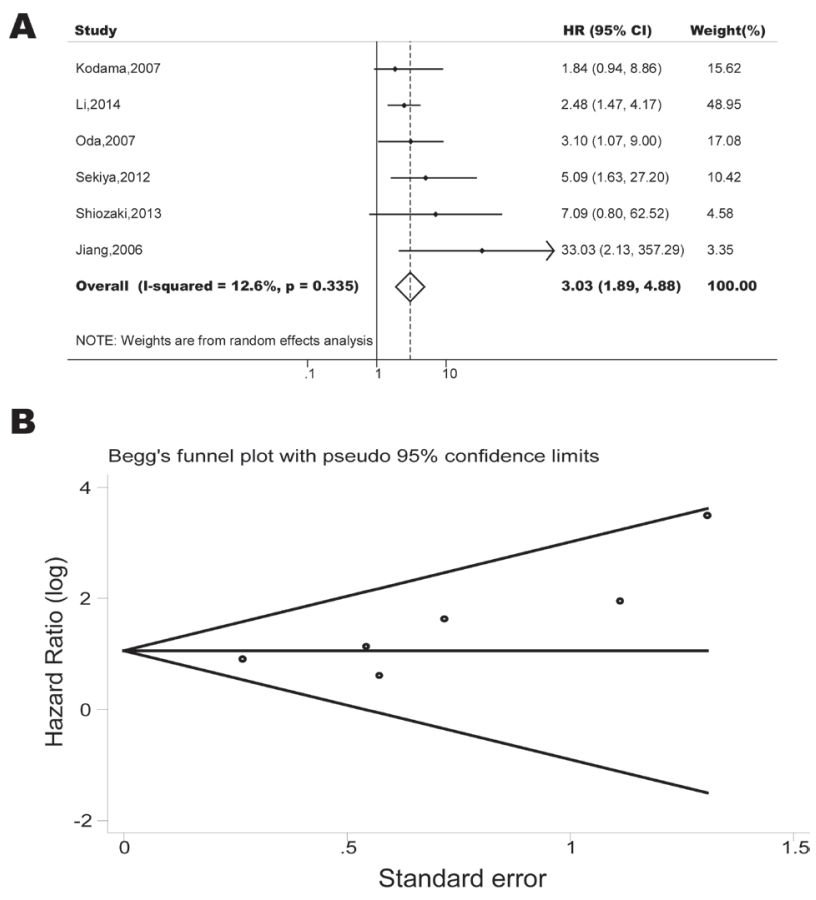

Figure 8: Forest plots show association between CXCR4 over-expression and PFS in gynecologic cancer. (A) Summary for all six trials, the estimates is 2.89(1.93-4.32) using fixed effects model. (B) Funnel plots showing association of CXCR4 and PFS in gynecologic cancer. Visual inspection of the Begg funnel plot did not identify substantial asymmetry. 
2.45, Figure 4)[10, 19-27, 30, 32, 33], colorectal cancer (4 studies, 263 patients, HR=2.69, 95\% CI, 1.70-4.26, Figure 5)[35, 38-40], esophageal cancer (5 studies, 760 patients , $\mathrm{HR}=1.59,95 \% \mathrm{CI}, 1.24-2.05$, Figure 6)[43, 45-48], renal cancer (4 studies, 488 patients, HR=3.98, 95\% CI, 2.267.01, Figure 7)[63-66], gynecologic cancer (6 studies, 466 patients, HR=3.03, 95\% CI, 1.89-4.88, Figure 8)[77-80, 82,83 ] and liver cancer ( 2 studies, 256 patients, $\mathrm{HR}=2.32$, 95\% CI, 1.73-3.10)[88, 89]. Based on the available data, the associations between CXCR4 over-expression and PFS were inconclusive in gastric cancer ( 1 studies, 26 patients, $\mathrm{HR}=3.42,95 \% \mathrm{CI}, 0.71-16.36)[53]$, head and neck cancer (1 studies, 71 patients, HR=1.19, 95\% CI, 0.56-2.54)[56], lung cancer ( 2 studies, 233 patients, $\mathrm{HR}=1.05,95 \% \mathrm{CI}$, 0.12-8.96)[8, 70], melanoma (2 studies, 103 patients, $\mathrm{HR}=1.42,95 \% \mathrm{CI}, 0.64-3.19)[73,75]$, pancreatic cancer (1 studies, 71 patients, $\mathrm{HR}=1.28,95 \% \mathrm{CI}, 0.90-1.83$ )[85]. Because of the small sample sizes of these five types of cancers, meaningful analysis of the role of CXCR4 on outcome in patients with these cancers were not possible.

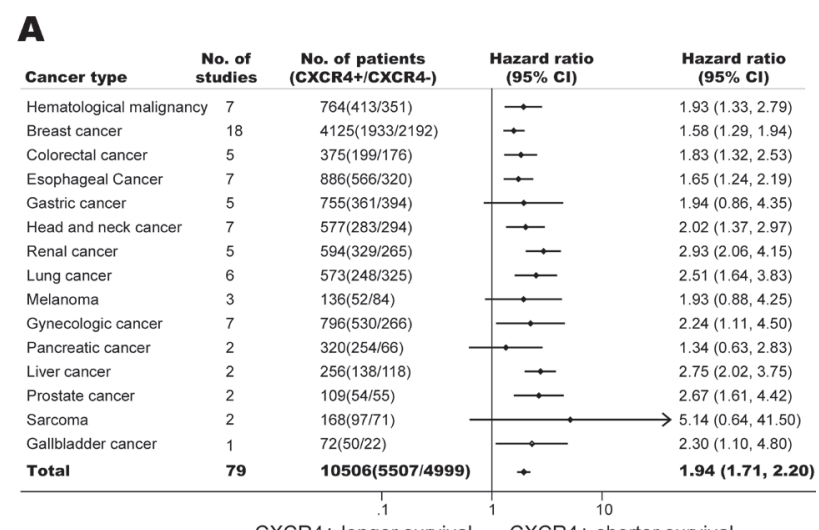

B

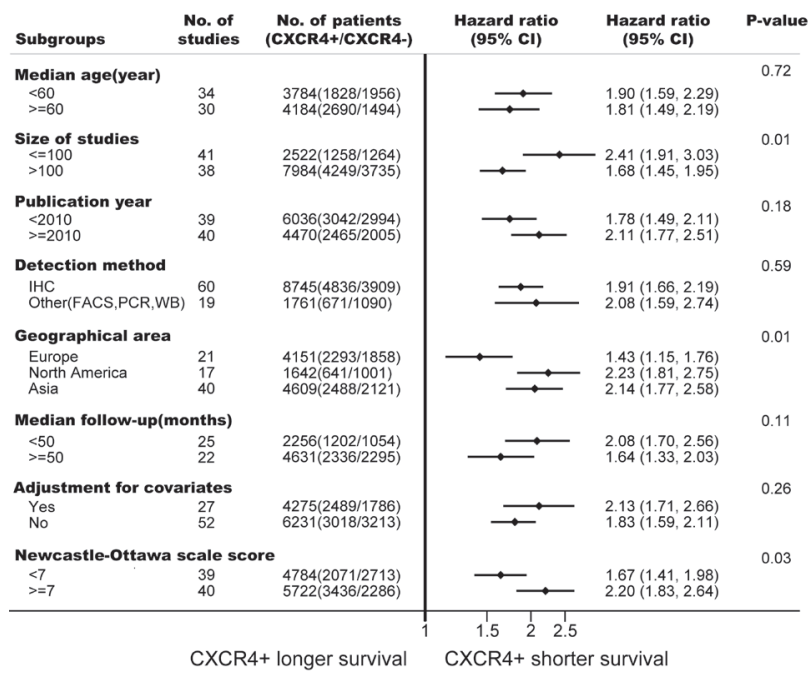

Figure 9: Association of CXCR4 over-expression and overall survival (OS). (A) Forest plot shows CXCR4 overexpression and OS in 15 types of cancers. (B) CXCR4 overexpression is associated with worse OS among cancer patients according to various characteristics.

\section{CXCR4 and OS}

Seventy-nine studies, with a total of 10,506 patients, included data on overall survival in 15 types of cancer. Of all the participants, 5507 (52\%) were CXCR4 overexpression. The overall quality of the included studies was examined, 40 studies $(51 \%)$ were at low risk of bias, and the rest 39 studies $(49 \%)$ were at high risk of bias. Twentyseven studies (34\%) had their outcomes adjust to different covariates. Geographically, 17 studies (22\%) including 1642 participants were conducted in the US and Canada, 1 study (1\%) including 104 participants were conducted in South America, 21 studies (27\%) including 4151
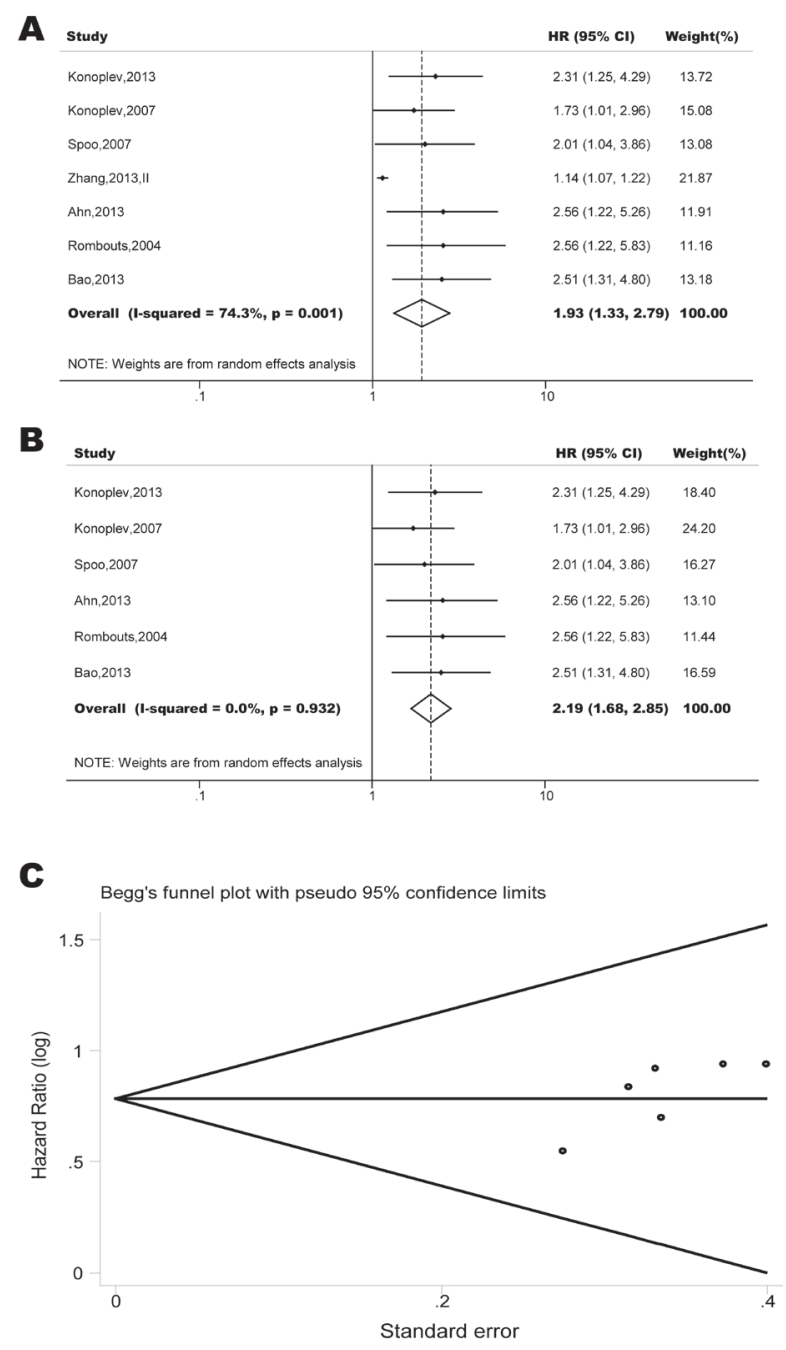

Figure 10: Forest plots show association between CXCR4 over-expression and overall survival (OS) in hematological malignancy. (A) Summary for all seven trials, the estimates is $1.18(1.11-1.26)$ using fixed effects model. (B) Excluding the only study focused on myelodysplastic syndrome (Zhang, 2012) yield results without significant heterogeneity. The estimate is 2.19(1.68-2.85) using fixed effects model. (C) Funnel plots showing association of CXCR4 and OS in hematological malignancy. Visual inspection of the Begg funnel plot did not identify substantial asymmetry. 
participants in Europe, and 40 studies (50\%) including 4609 participants in Asia.

As shown in Figure 9A, CXCR4 over-expression was statistically associated with a poor OS $(\mathrm{HR}=1.94$, 95\% CI, 1.71-2.20) when including all 79 studies[9-34, $36,37,39-62,64-69,71,72,74-92]$; however, there was significant heterogeneity $\left(\mathrm{I}^{2}=73 \%, \mathrm{p}<0.01\right)$. Metainfluence analysis did not suggest undue influence of any single study. In the eight predefined subgroup analyses of OS (Figure 9B), the prognostic effects were similar between the subgroups by line of levels of adjustment, age, follow-up period, detection methods and publication year. However, the subgroup results by risk of bias (NewcastleOttwa scale scores); size of studies and geographical area appeared to be discordant. These may partly explain the substantial heterogeneities in our meta-analysis.

The pooled model showed a significantly shorter OS with CXCR4 over-expression patients in hematological malignancy ( 7 studies, 764 patients, $\mathrm{HR}=1.93,95 \% \mathrm{CI}$, 1.33-2.79, Figure 10)[12-18], breast cancer (18 studies, 4125 patients, $\mathrm{HR}=1.58,95 \% \mathrm{CI}, 1.29-1.94$, Figure 11) [10, 11, 19-34], colorectal cancer (5 studies, 375 patients, $\mathrm{HR}=1.83,95 \%$ CI, 1.32-2.53, Figure 12)[36, 37, 39-41], esophageal cancer ( 7 studies, 886 patients, HR $=1.65,95 \%$ CI, 1.24-2.19, Figure 13)[42-48], head and neck cancer (7 studies, 577 patients, HR=2.02, 95\% CI, 1.37-2.97, Figure 14)[54-60], renal cancer (5 studies, 594 patients, $\mathrm{HR}=2.93,95 \% \mathrm{CI}, 2.06-4.15$, Figure 15)[61, 62, 64-66], lung cancer ( 6 studies, 573 patients, $\mathrm{HR}=2.51,95 \% \mathrm{CI}$, 1.64-3.83, Figure 16)[8, 67-69, 71, 72], gynecologic cancer ( 7 studies, 796 patients, HR=2.24, 95\% CI, 1.114.50, Figure 17) [9, 77-82] , liver cancer (2 studies, 256 patients, $\mathrm{HR}=2.75,95 \% \mathrm{CI}, 2.02-3.75)[88,89]$, prostate cancer (2 studies, 109 patients, HR=2.67, 95\% CI, 1.61-4.42)[86, 87] and gallbladder cancer (1 studies, 72 patients, $\mathrm{HR}=2.30,95 \% \mathrm{CI}, 1.10-4.80)[92]$. Based on the available data, the associations between CXCR4 overexpression and PFS were inconclusive in gastric cancer (5 studies, 755 patients, $\mathrm{HR}=1.94,95 \% \mathrm{CI}, 0.86-4.35$, figure 18)[49-53], melanoma (3 studies, 136 patients, $H R=1.93$, 95\% CI, 0.88-4.25, Figure 19)[74-76], pancreatic cancer (2 studies, 320 patients, HR=1.34, 95\% CI, 0.63-2.83)[84, 85 ] and sarcoma ( 2 studies, 168 patients, $\mathrm{HR}=5.14,95 \%$ CI, 0.64-41.50)[90, 91]. The insignificant associations between these subtypes of cancer and clinical outcome might be due to the limited available data.

\section{DISCUSSION}

CXCR4 has been implicated in the etiology of a substantial number of tumors because this receptor is thought to play a key role in chemotaxis, invasion, angiogenesis, metastasis and proliferation. Many agents against CXCR4 are currently under development[2]. However, there still remain unanswered questions about the direction and magnitude of effect of CXCR4 on outcome and whether the outcome is consistent among different subgroups. Here, we report a systematic review of 11,032 patients included in 85 different studies. Our study shows that the expression of CXCR4 is a significant and independent biomarker of worse prognosis in cancer.

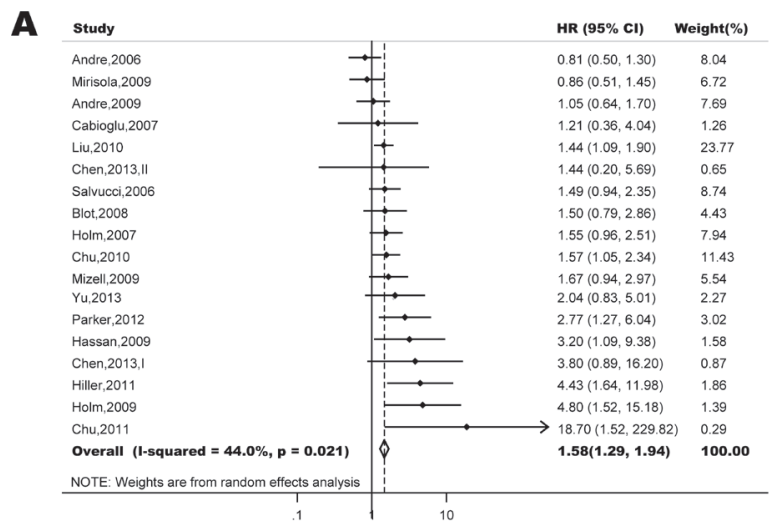

B

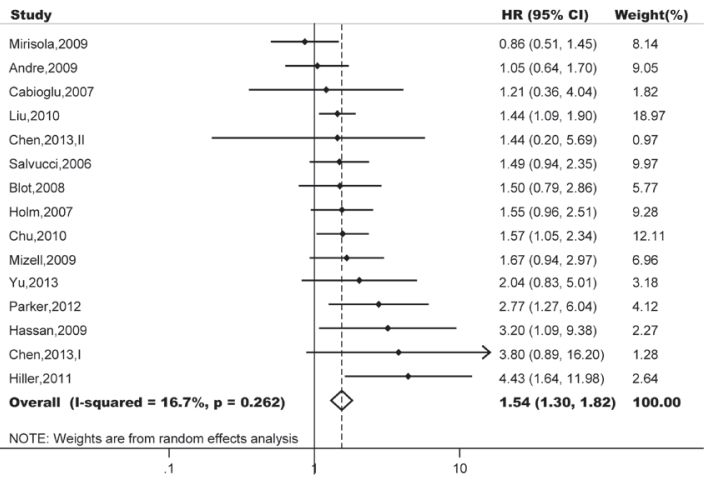

C Begg's funnel plot with pseudo $95 \%$ confidence limits

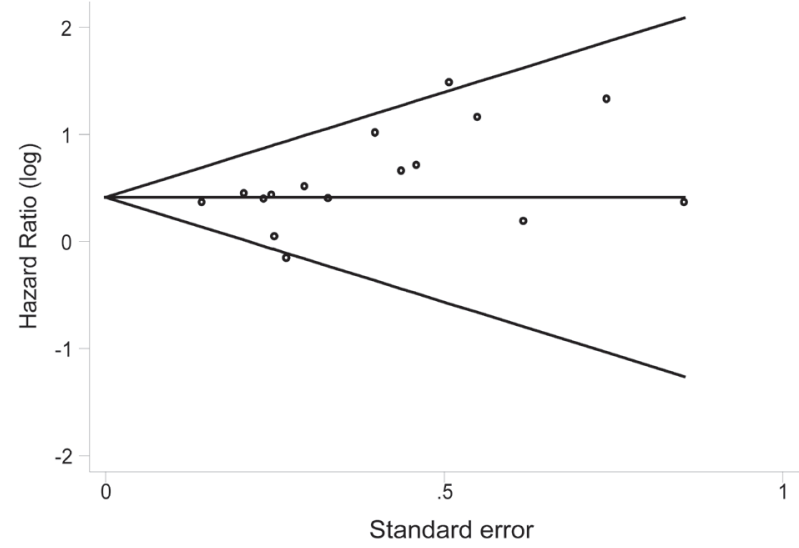

Figure 11: Forest plots show association between CXCR4 over-expression and OS in breast cancer. (A) Summary for all nineteen trials, the estimates is 1.47(1.29-1.69) using fixed effects model. (B) Although three studies appeared to be outliers (Andre, 2006; Chu, 2011; Holm, 2009), we did not find clinical heterogeneity justifying their exclusion. Excluding three studies yield similar results but without significant heterogeneity. The estimate is $1.52(1.31-1.75)$ using fixed effects model. (C) Funnel plots showing association of CXCR4 and OS in breast cancer. Visual inspection of the Begg funnel plot did not identify substantial asymmetry. 

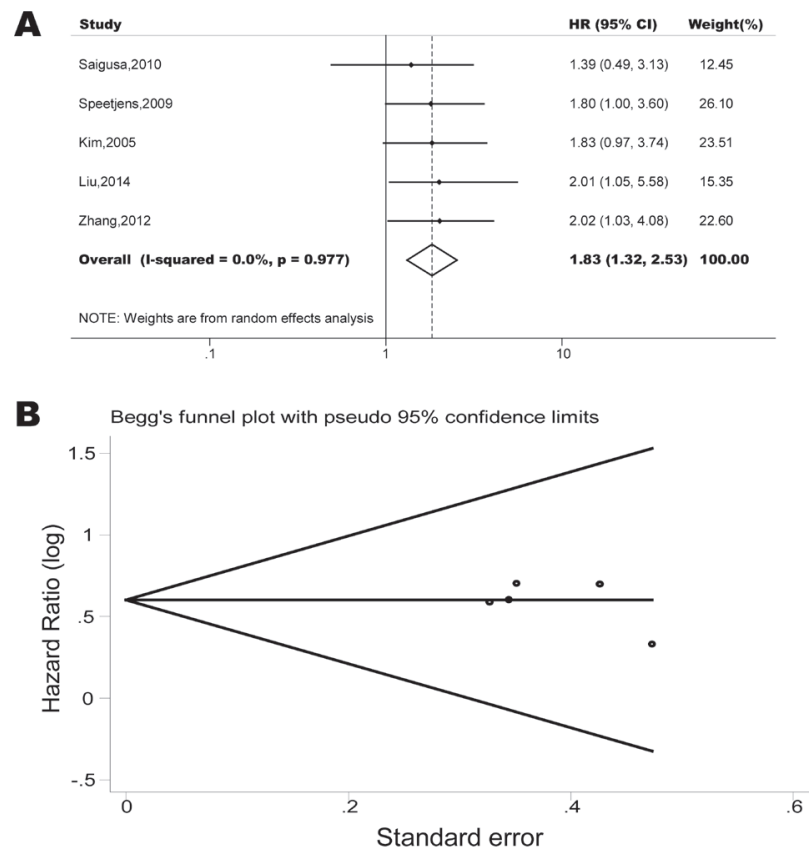

Figure 12: Forest plots show association between CXCR4 over-expression and OS in colorectal cancer. (A) Summary for all five trials, the estimates is $1.83(1.32-2.53)$ using fixed effects model. (B) Funnel plots showing association of CXCR4 and OS in colorectal cancer. Visual inspection of the Begg funnel plot did not identify substantial asymmetry.

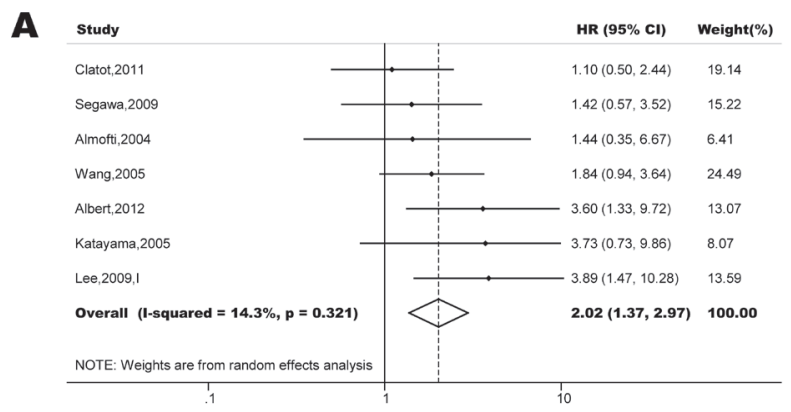

B

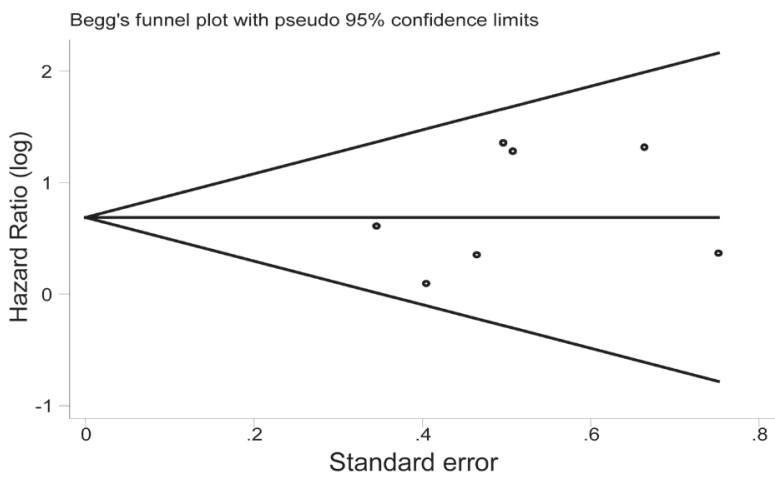

Figure 14: Forest plots show association between CXCR4 over-expression and OS in head and neck cancer. (A) Summary for all seven trials, the estimates is 2.00(1.40-2.81) using fixed effects model. (B) Funnel plots showing association of CXCR4 and OS in head and neck cancer. Visual inspection of the Begg funnel plot did not identify substantial asymmetry.
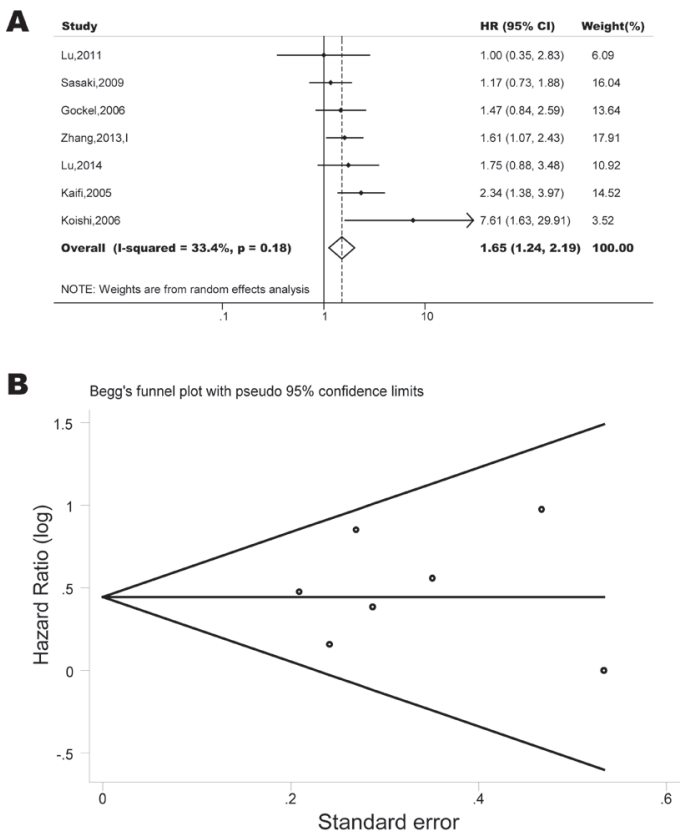

Figure 13: Forest plots show association between CXCR4 over-expression and OS in esophageal cancer. (A) Summary for all eight trials, the estimates is 1.63(1.22-2.09) using fixed effects model. (B) Funnel plots showing association of CXCR4 and OS in esophageal cancer. Visual inspection of the Begg funnel plot did not identify substantial asymmetry.
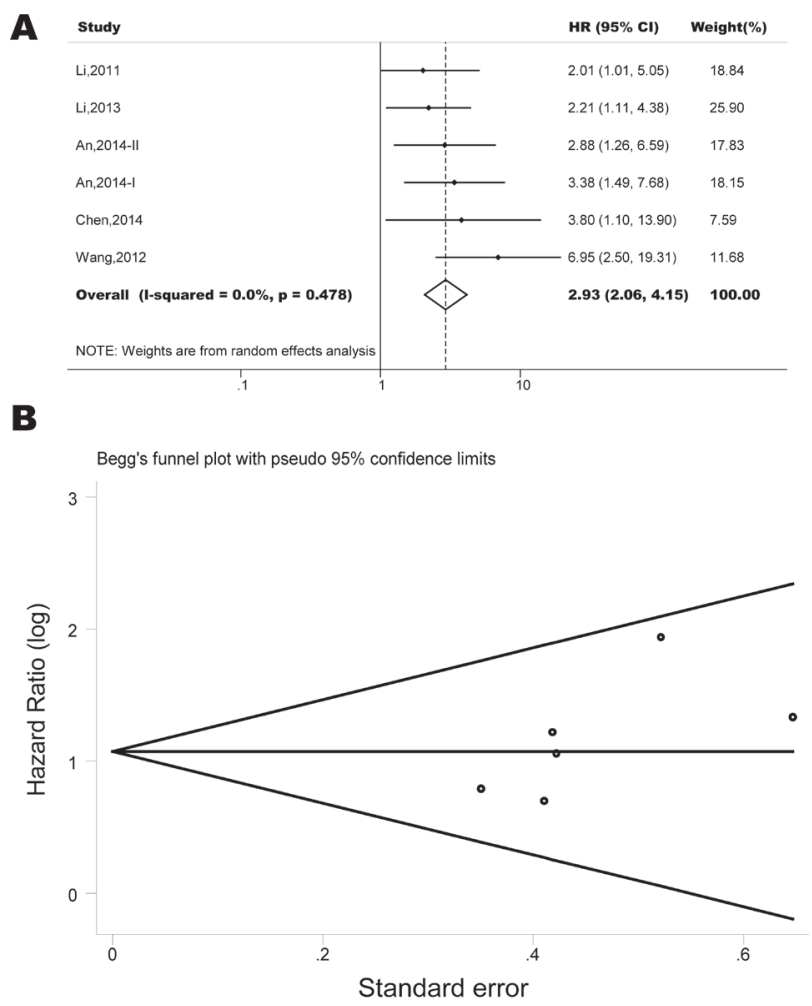

Figure 15: Forest plots show association between CXCR4 over-expression and OS in renal cancer. (A) Summary for all six trials, the estimates is $2.93(2.06-4.15)$ using fixed effects model. (B) Funnel plots showing association of CXCR4 and OS in renal cancer. Visual inspection of the Begg funnel plot did not identify substantial asymmetry. 
Table 2: Studies evaluating anti-human C-X-C chemokine receptor type 4 (CXCR4) therapeutic strategies in cancer (Clinical trials involving Plerixafor, the only CXCR4 antagonist approved by FDA, are not included in this table because of the limited space). BMS-936564 is monoclonal antibody against CXCR4. LY2510924, BL-8040, MSX-122, POL6326 and TG-0054 are CXCR4 antagonists.

\section{Study \\ Sponsor}

NCT01359657 Bristol-Myers Squibb

NCT01120457 Bristol-Myers Squibb

NCT00591682 Metastatix Inc

NCT01837095 Polyphor Ltd.

NCT01010880 Biokine Therapeutics Ltd

NCT01413568 Polyphor Ltd.

Multiple Myeloma Follicular Lymphoma

Multiple Myeloma

Hodgkin's Disease,
Acute Myelogenous Leukemia, Diffuse Large B-Cell Leukemia, Chronic Lymphocytic Leukemia,

Advanced Solid Tumors Metastatic Breast Cancer

Acute Myelogenous Leukemia, Acute Lymphoblastic Leukemia, Chronic Myelogenous Leukemia, Non-Hodgkin's Lymphoma,

Chronic Lymphocytic Leukemia, Multiple Myeloma, Myelodysplastic Syndrome, Myeloproliferative Disorder

\begin{tabular}{|c|c|}
\hline NCT02115672 & Sheba Medical Center \\
\hline NCT01018979 & $\begin{array}{l}\text { TaiGen Biotechnology } \\
\text { Ltd. }\end{array}$ \\
\hline NCT01105403 & Polyphor Ltd. \\
\hline NCT01458288 & $\begin{array}{l}\text { TaiGen Biotechnology } \\
\text { Ltd. }\end{array}$ \\
\hline NCT01838395 & BioLineRx, Ltd. \\
\hline NCT02104427 & $\begin{array}{l}\text { TaiGen Biotechnology } \\
\text { Ltd. }\end{array}$ \\
\hline NCT01439568 & Eli Lilly and Company \\
\hline NCT01391130 & Eli Lilly and Company \\
\hline
\end{tabular}

Chronic Myeloid Leukemia Multiple Myeloma,

Non-Hodgkin Lymphoma,

Hodgkin Disease

Multiple Myeloma

Multiple Myeloma,

Non-Hodgkin Lymphoma,

Hodgkin Disease

Acute Myeloid Leukemia

Multiple Myeloma,

Non-Hodgkin Lymphoma, Hodgkin Disease

Small Cell Lung Carcinoma

Metastatic Renal Cell Carcinoma Phase II
Phase

Phase I

Phase I

Phase I

Phase I

MSX-122

POL6326

Phase I/II BL-8040, under the name BKT140 + Dexamethasone

BMS-936564
Intervention(s)

Arm A: BMS-936564 + Lenalidomide + Dexamethasone Arm B: BMS-936564 + Bortezomib

Phase I/II POL6326

Phase I/II BL-8040

Phase II TG-0054

Phase II POL6326

Phase II TG-0054

Phase II BL-8040 + Ara-C

Phase II TG-0054 combined with G-CSF

Phase II Arm A: LY2510924 + Carboplatin + Etoposide Arm B: Carboplatin + Etoposide Arm A: LY2510924 + Sunitinib Arm B: Sunitinib
This result may suggest that the development of strategies against CXCR4 could be a reasonable therapeutic approach.

\section{CXCR4 as an independent prognostic biomarker in cancer}

CXCR4 is expressed in various different tumor types and has been considered the most widely expressed chemokine receptor in most cancers. In current metaanalysis, we revealed that CXCR4 over-expression were generally associated with poorer survival in most cancer. For certain types of cancer such as gastric cancer, sarcoma, pancreatic cancer and melanoma, these associations are inconclusive. We believe these insignificances were due to the small size of available studies. Further investigations were needed to clarify the role of CXCR4 as a biomarker for prognosis in these types of cancer.

At present, it is well accepted that CXCR4 over- expression is a risk factor of short survivals in certain types of cancer. However, whether CXCR4 over-expression is independently associated with worse clinical outcome remains controversial. Results from our sensitivity analysis restrict to studies adjusted for established confounders such as age, gender and tumor stage, suggest that CXCR4 over-expression is probably an independent prognostic biomarker. Moreover, if CXCR4 was merely an early marker, it would be more likely to occur just the time of onset of cancer. In fact, the mean length of follow-up in primary studies ranged from 8 to 167 months. Such a large interval further supports the hypothesis that CXCR4 over-expression is an independent prognostic biomarker.

The underlying mechanisms involved in the association between CXCR4 over-expression and survivals are uncertain. One possible explanation is the "CXCL12/CXCR4 chemokine axis hypothesis"[93]. In the past decades, more and more evidence suggests the stroma contributes to the growth and invasion of tumors. 
Figure 16: Forest plots show association between CXCR4 over-expression and OS in lung cancer. (A) Summary for all six trials, the estimates is 2.40(1.76-3.25) using fixed effects model. (B) Funnel plots showing association of CXCR4 and OS in lung cancer. Visual inspection of the Begg funnel plot did not identify substantial asymmetry.
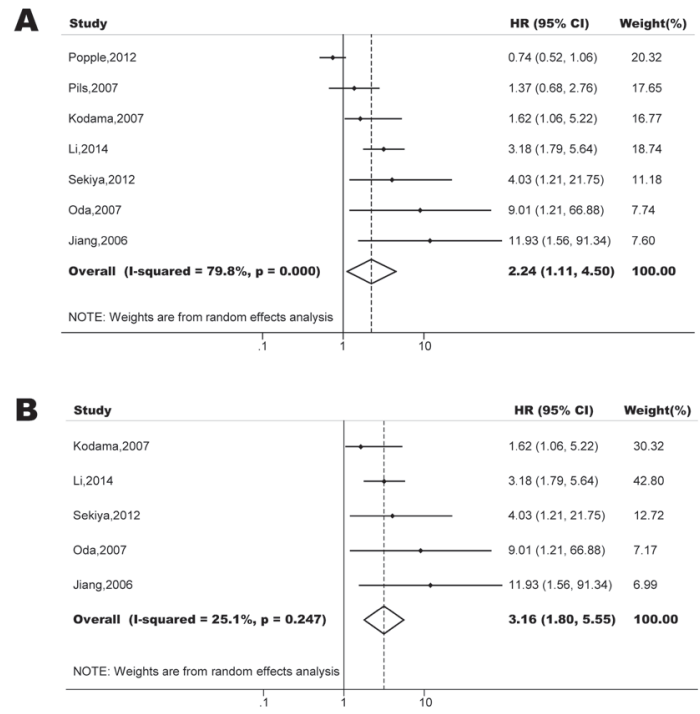

C

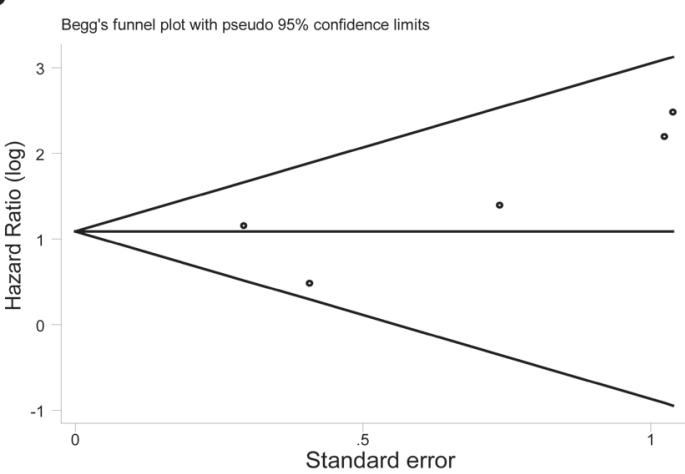

Figure 17: Forest plots show association between CXCR4 over-expression and OS in gynecologic cancer. (A) Summary for all seven trials, the estimates is 1.32(1.03-1.71) using fixed effects model. (B) Excluding two studies (Popple, 2012; Pils, 2007) yield results without significant heterogeneity. The estimate is 3.00(1.85-4.55) using fixed effects model. (C) Funnel plots showing association of CXCR4 and OS in gynecologic cancer. Visual inspection of the Begg funnel plot did not identify substantial asymmetry.

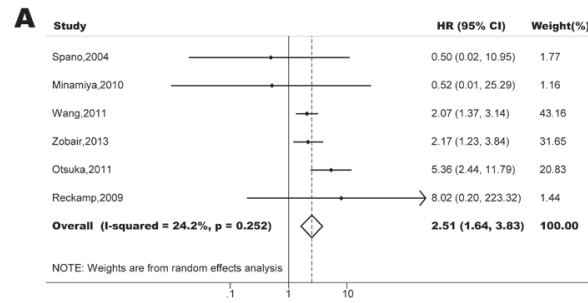

$\mathbf{B}$

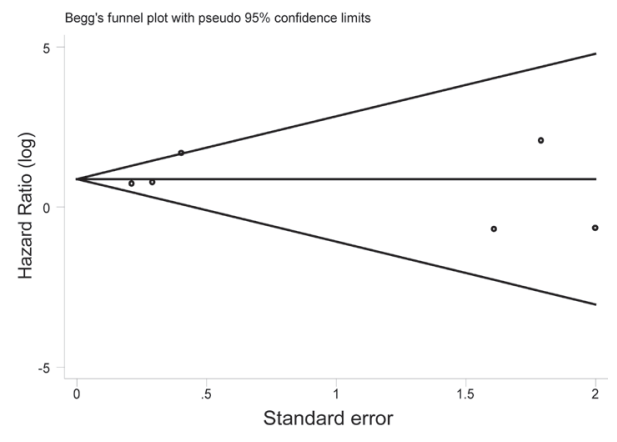

A study

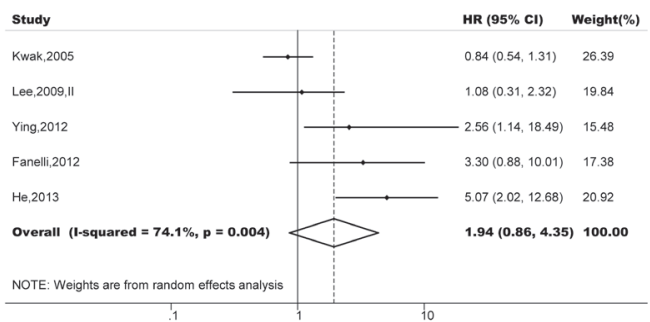

B study

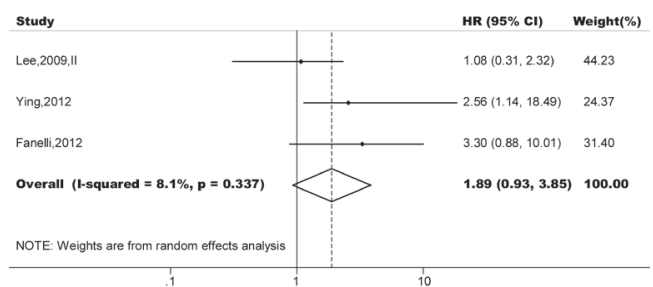

C

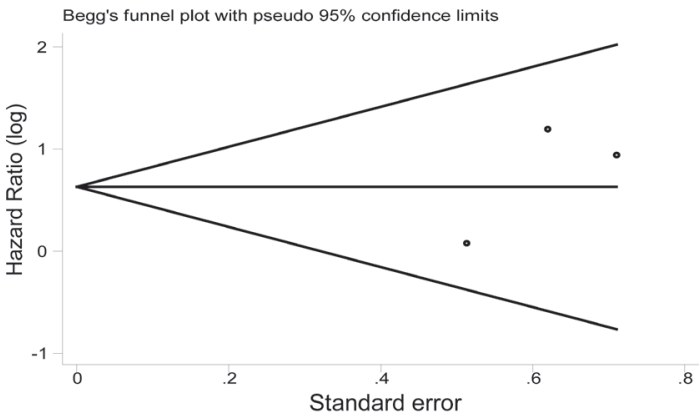

Figure 18: Forest plots show association between CXCR4 over-expression and OS in gastric cancer. (A) Summary for all five trials, the estimates is $1.33(0.94-1.87)$ using fixed effects model. (B) Although two studies appeared to be outliers (Koishi, 2006; Sasaki, 2009), we did not find clinical heterogeneity justifying their exclusion. Excluding two studies yield results without significant heterogeneity. The estimate is 1.88(0.95-3.70) using fixed effects model. (C) Funnel plots showing association of CXCR4 and OS in gastric cancer. Visual inspection of the Begg funnel plot did not identify substantial asymmetry. 
In support of this notion, it was demonstrated that of CXCR4 may play a critical role as a chemoattractant in cancer development possibly at the level of the tumor niche [94]. The data reveals that both CXCL12 expression by fibroblasts and CXCR4 expression on cancer cells, within hypoxic areas of tumors, trigger tumor cell growth, motility and invasiveness. In addition, the stroma cells from specialized microenvironments actually modulate CXCR4 expression, which is responsible for tumorigenesis and tumor progression. Obviously, the tumor and stroma cell interactions is truly reciprocal; while stroma cells may support tumors, tumor cells in turn modulate the microenvironments. Hence, CXCR4 and CXCL12 form an important signaling axis between tumor cells and their microenvironment, with the interaction influencing the adhesion, migration and invasion of tumor cells, reflecting the strong association of CXCR4 with cancer metastasis.

\section{Strengths and implications of findings}

Our meta-analyses have several important implications. First, the generalisability of our findings has been enhanced by the involvement of data from over 10,000 participants in 14 nations. Second, the association of CXCR4 over-expression with survivals persists and remains statistically significant based on various classification criteria. Third, all of the analyses were conducted by random-effects model and fixedeffects model, both models showed similar results, which indicated that the statistic results were robust.

In addition to being a prognostic biomarker, our results are of clinical relevance in view of the emergence of new drugs targeting CXCR4. Currently, only one CXCR4 antagonist, plerixafor is approved by FDA but several others are being investigated in clinical phase I/II trials (Table 2). Plerixafor in combination with granulocyte-colony stimulating factor (G-CSF) has been approved as mobiliser of haematopoietic CD34+ cells
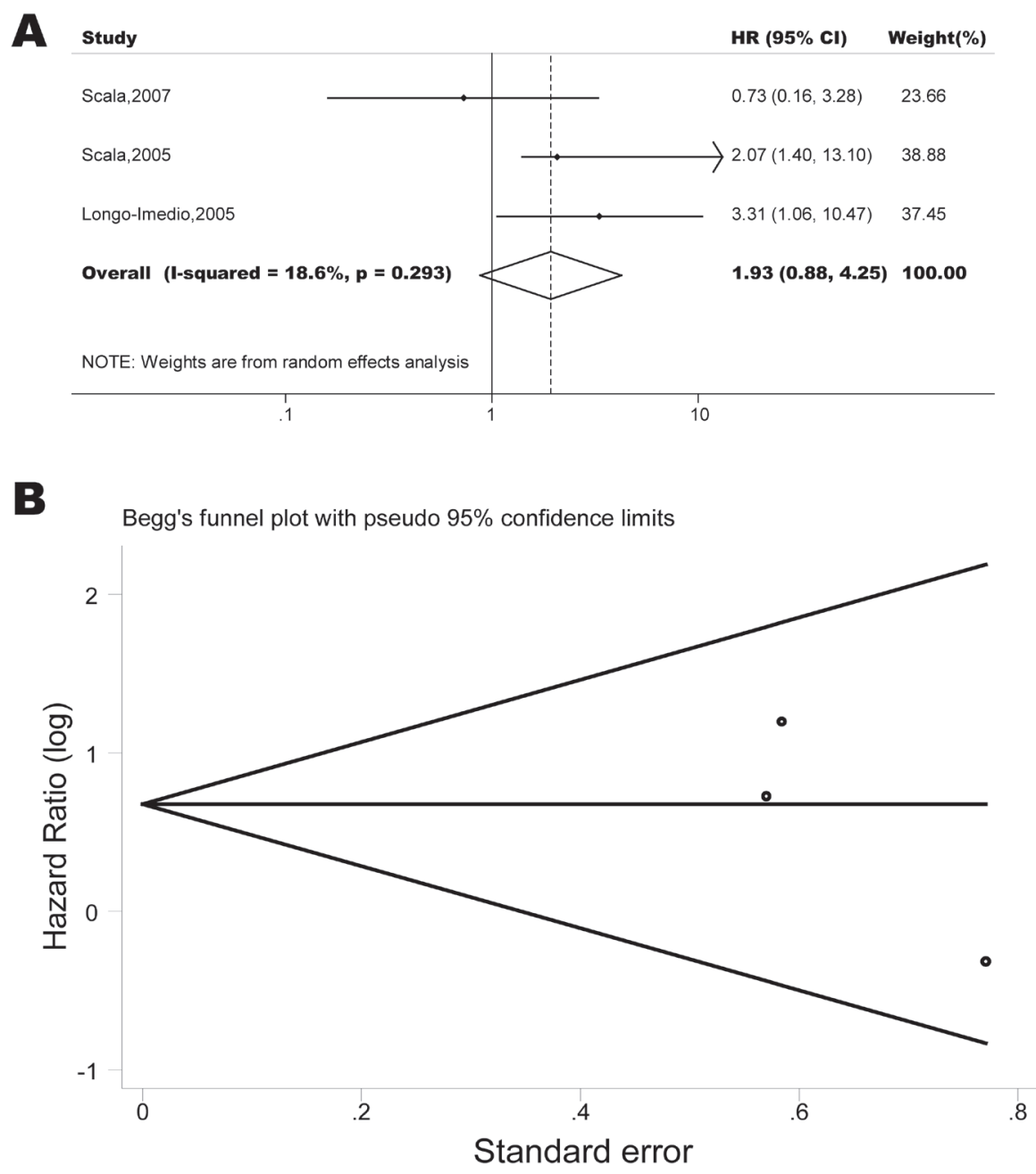

Figure 19: Forest plots show association between CXCR4 over-expression and OS in melanoma. (A) Summary for all three trials, the estimates is 1.96(0.97-3.99) using fixed effects model. (B) Funnel plots showing association of CXCR4 and OS in melanoma. Visual inspection of the Begg funnel plot did not identify substantial asymmetry. 
from the bone marrow to the circulation for patients with non-Hodgkin's lymphoma and multiple myeloma[2]. Also, it is currently involved in a number of clinical trials for the prevention of growth and metastasis of many different cancers. Besides the CXCR4 inhibitors listed in table 2, CTCE-9908, one CXCL12 peptide analogue, was tested as mono-treatment in advanced solid tumor. In July 2005, FDA assigned orphan drug status to this drug for the treatment of osteosarcoma, but there was no further news on advancement of clinical trial although phase I/II trial had been completed in 2008[95]. CXCR4 overexpression was associated with both PFS and OS in seven subtypes of cancers (hematological malignancy, breast cancer, colorectal cancer, esophageal cancer, renal cancer, gynecologic cancer, and liver cancer). Only three disease sites had more than five studies supporting the significance of CXCR4 in impacting both PFS and OS (breast cancer, gynecologic cancer and hematological malignancy). So these organ systems might be the potential targets in the future clinical interventions.

\section{Limitations of study}

Despite of the strengths mentioned above, this meta-analysis also has some limitations. First, because this is a literature-based analysis, it is compromised by the potential for publication bias, whereby predominantly positive results were published, thus inflating our estimate for the association between CXCR4 and poor outcome. The languages of the published studies included in this meta-analysis were restricted to English. Other potentially eligible studies which met our inclusion criteria cannot be included. Second, this is a systematic review and meta-analysis of literatures, we were only able to extract population-level rather than individual patient level data. This reduced our ability to test for associations between variables in specific subgroups and also limited our ability to assess for sources of heterogeneity. Third, there was no accepted and validated method for assessment of CXCR4 expression. Therefore, there might be substantial heterogeneity, which might not be fully accounted for by our use of random-effects modeling. An internationally accepted and validated method for CXCR4 testing was needed. Fourth, the survival analysis was not performed by multivariate analyses in many studies reported; we calculated or estimated the HR from available data or Kaplan-Meier curves. Finally, there was marked heterogeneity in patient populations, clinical treatment method and follow-up of patients. Random-effects modeling and sensitivity analyses were conducted to address this heterogeneity, but these statistical methods may not be sufficient.

\section{MATERIALS AND METHODS}

\section{Search strategy and selection of studies}

This meta-analysis was carried out in accordance with the Preferred Reporting Items for Systematic Reviews and Meta-Analyses (PRISMA) statement [96]. Relevant studies published before June, 2014 (date last searched), were identified through electronic searches using PubMed and Embase. The following search terms were used: 1) cancer, tumor, neoplasm, carcinoma; 2) CXCR4, CXCR-4, C-X-C chemokine receptor type 4, CXC chemokine receptor 4, fusin, LESTR, HUMSTR, CD184, cluster of differentiation 184. Electronic searches were supplemented by scanning reference lists of articles identified for all relevant studies (including review articles), by hand searching of relevant journals and by correspondence with study investigators. In addition to full publications, original studies in the form of conference abstracts and letters were included to capture grey literature. Each study was assessed for inclusion by two or three reviewers independently and discrepancies within the reviewing pair were resolved via discussion.

All initially identified studies were screened of titles and/or abstracts; then full texts were retrieved for studies that satisfied all selection criteria. Studies were considered eligible if they met the following criteria: 1) the exposure of interest were cancer and CXCR4;2) the outcome of interests were progression-free survival and overall survival; 3 ) hazard ratio (HR) and the corresponding 95\% confidence interval (CI) (or data sufficient to calculate them) were reported; and 4) exclusion of letters to the editor, reviews, and articles published in non-English language books or papers.

\section{Data Collection and extraction}

We used a predesigned data abstraction form to extract relevant information. The following details were extracted: First author's full name; year of publication; country of origin; cancer type, median age at the time of diagnosis, median duration of follow-up, period of followup, method to detect CXCR4, total number of patients, number of CXCR4 over-expression patients and controls, method for CXCR4 assessment and cutoff for defining CXCR4 as over-expressed, reported adjusted factors and assessments of outcomes (HR and the corresponding 95\% $\mathrm{CI}$ of PFS and/or OS). When the statistical variables were not given explicitly in an article, they were estimated from available data using methods reported by Tierney et al[97], or abstracted from other published reviews[98-100]. 


\section{Assessment of risk of bias}

We used the Newcastle-Ottawa Scale to assess the risk of bias[101]. This scale uses a star system (with a maximum of nine stars) to evaluate a study in three domains: selection of participants, comparability of study groups, and the ascertainment of outcomes of interest. We judged studies that received a score of seven or more stars to be at low risk of bias, and those that scored less than seven to be at high risk of bias. This cutoff point was chosen according to the distribution of relative quality scores of all included studies.

\section{Statistical analysis}

Homogeneity of HRs across the studies was tested by $\mathrm{Q}$ statistic (significance level at $\mathrm{p}<0.05$ ). The $\mathrm{I}^{2}$ statistic, a quantitative measure of inconsistency across studies[102], was also calculated. The combined risk estimates were computed by fixed-effect models and random-effect models [103].Fixed-effect models $(\mathrm{P}>0.1$ and $\mathrm{I}^{2}<50 \%$ ) assume that the differences between the results of various studies are due to chance. Random-effect models ( $\mathrm{P}<0.1$ or $\left.\mathrm{I}^{2}>50 \%\right)$ assume that the results could genuinely differ between studies. When heterogeneity is present, the random-effect model is considered to be more appropriate than a fixed-effect model, resulting in wider intervals and a more conservative estimate of treatment effect.

Because characteristics of populations, ascertainment of different cancer subtype, and adjustments for confounding factors were not consistent between studies, we further conducted a sensitivity analysis by removing one or several studies to explore possible explanations for heterogeneity and to examine the influence of various exclusion criteria on the overall risk estimate.

Potential publication bias was assessed by visual inspection of the Begg funnel plots. We also performed the Begg rank correlation test at the $p<0.10$ level of significance[104]. All analyses were performed using STATA version 12.0 (StataCorp LP, Texas). $\mathrm{p}<0.05$ was considered statistically significant. All statistical tests were two-sided.

\section{CONCLUSIONS}

Based on our review of 85 studies in over 11,000 patients with cancer, we show that over-expression of CXCR4 is associated with worse prognosis in terms of OS and PFS in different types of tumors, which suggests that the development of strategies against this receptor could be a reasonable therapeutic approach.

\section{ACKNOWLEDGEMENTS}

No potential conflicts of interest were disclosed.

\section{Editorial note}

This paper has been accepted based in part on peerreview conducted by another journal and the authors' response and revisions as well as expedited peer-review in Oncotarget.

\section{REFERENCES}

1. Jemal A, Bray F, Center MM, Ferlay J, Ward E and Forman D. Global cancer statistics. CA Cancer J Clin. 2011; 61(2):69-90.

2. Debnath B, Xu S, Grande F, Garofalo A and Neamati N. Small molecule inhibitors of CXCR4. Theranostics. 2013; 3(1):47-75.

3. Caruz A, Samsom M, Alonso JM, Alcami J, Baleux F, Virelizier JL, Parmentier M and Arenzana-Seisdedos F. Genomic organization and promoter characterization of human CXCR4 gene. FEBS Lett. 1998; 426(2):271-278.

4. Kucia M, Jankowski K, Reca R, Wysoczynski M, Bandura L, Allendorf DJ, Zhang J, Ratajczak J and Ratajczak MZ. CXCR4-SDF-1 signalling, locomotion, chemotaxis and adhesion. J Mol Histol. 2004; 35(3):233-245.

5. Saini V, Marchese A and Majetschak M. CXC chemokine receptor 4 is a cell surface receptor for extracellular ubiquitin. The Journal of biological chemistry. 2010; 285(20):15566-15576.

6. Lippitz BE. Cytokine patterns in patients with cancer: a systematic review. The Lancet Oncology. 2013; 14(6):e218228.

7. Zlotnik A. New insights on the role of CXCR4 in cancer metastasis. The Journal of pathology. 2008; 215(3):211213.

8. Minamiya $\mathrm{Y}$, Saito H, Takahashi N, Ito M, Imai K, Ono T, Motoyama S and Ogawa J. Expression of the chemokine receptor CXCR4 correlates with a favorable prognosis in patients with adenocarcinoma of the lung. Lung cancer. 2010; 68(3):466-471.

9. Popple A, Durrant LG, Spendlove I, Rolland P, Scott IV, Deen S and Ramage JM. The chemokine, CXCL12, is an independent predictor of poor survival in ovarian cancer. British journal of cancer. 2012; 106(7):1306-1313.

10. Andre F, Cabioglu N, Assi H, Sabourin JC, Delaloge S, Sahin A, Broglio K, Spano JP, Combadiere C, Bucana C, Soria JC and Cristofanilli M. Expression of chemokine receptors predicts the site of metastatic relapse in patients with axillary node positive primary breast cancer. Ann Oncol. 2006; 17(6):945-951.

11. Salvucci O, Bouchard A, Baccarelli A, Deschenes J, Sauter G, Simon R, Bianchi R and Basik M. The role of 
CXCR4 receptor expression in breast cancer: a large tissue microarray study. Breast Cancer Res Treat. 2006; 97(3):275-283.

12. Ahn JY, Seo K, Weinberg OK and Arber DA. The prognostic value of CXCR4 in acute myeloid leukemia. Appl Immunohistochem Mol Morphol. 2013; 21(1):79-84.

13. Bao L, Lai Y, Liu Y, Qin Y, Zhao X, Lu X, Jiang Q, Lu $\mathrm{J}$ and Huang $\mathrm{X}$. CXCR4 is a good survival prognostic indicator in multiple myeloma patients. Leuk Res. 2013; 37(9):1083-1088.

14. Konoplev S, Rassidakis GZ, Estey E, Kantarjian H, Liakou CI, Huang X, Xiao L, Andreeff M, Konopleva M and Medeiros LJ. Overexpression of CXCR4 predicts adverse overall and event-free survival in patients with unmutated FLT3 acute myeloid leukemia with normal karyotype. Cancer. 2007; 109(6):1152-1156.

15. Konoplev S, Lin P, Yin CC, Lin E, Nogueras Gonzalez GM, Kantarjian HM, Andreeff M, Medeiros LJ and Konopleva M. CXC chemokine receptor 4 expression, CXC chemokine receptor 4 activation, and wild-type nucleophosmin are independently associated with unfavorable prognosis in patients with acute myeloid leukemia. Clin Lymphoma Myeloma Leuk. 2013; 13(6):686-692.

16. Rombouts EJ, Pavic B, Lowenberg B and Ploemacher RE. Relation between CXCR-4 expression, Flt3 mutations, and unfavorable prognosis of adult acute myeloid leukemia. Blood. 2004; 104(2):550-557.

17. Spoo AC, Lubbert M, Wierda WG and Burger JA. CXCR4 is a prognostic marker in acute myelogenous leukemia. Blood. 2007; 109(2):786-791.

18. Zhang Y, Guo Q, Zhao H, Zhao D, Wu X, Zhao W, Wang Y, Xia B and Da W. Expression of CXCR4 is an independent prognostic factor for overall survival and progression-free survival in patients with myelodysplastic syndrome. Med Oncol. 2013; 30(1):341.

19. Holm NT, Byrnes K, Li BD, Turnage RH, Abreo F, Mathis JM and Chu QD. Elevated levels of chemokine receptor CXCR4 in HER-2 negative breast cancer specimens predict recurrence. J Surg Res. 2007; 141(1):53-59.

20. Mirisola V, Zuccarino A, Bachmeier BE, Sormani MP, Falter J, Nerlich A and Pfeffer U. CXCL12/SDF1 expression by breast cancers is an independent prognostic marker of disease-free and overall survival. Eur J Cancer. 2009; 45(14):2579-2587.

21. Chu QD, Panu L, Holm NT, Li BD, Johnson LW and Zhang $\mathrm{S}$. High chemokine receptor CXCR4 level in triple negative breast cancer specimens predicts poor clinical outcome. J Surg Res. 2010; 159(2):689-695.

22. Chu QD, Holm NT, Madumere P, Johnson LW, Abreo F and $\mathrm{Li} \mathrm{BD}$. Chemokine receptor CXCR4 overexpression predicts recurrence for hormone receptor-positive, nodenegative breast cancer patients. Surgery. 2011; 149(2):193199.

23. Blot E, Laberge-Le Couteulx S, Jamali H, Cornic M,
Guillemet C, Duval C, Hellot MF, Pille JY, Picquenot $\mathrm{JM}$ and Veyret C. CXCR4 membrane expression in nodenegative breast cancer. Breast J. 2008; 14(3):268-274.

24. Andre F, Xia W, Conforti R, Wei Y, Boulet T, Tomasic G, Spielmann M, Zoubir M, Berrada N, Arriagada R, Hortobagyi GN, Hung MC, Pusztai L, Delaloge S, Michiels $\mathrm{S}$ and Cristofanilli M. CXCR4 expression in early breast cancer and risk of distant recurrence. Oncologist. 2009; 14(12):1182-1188.

25. Holm NT, Abreo F, Johnson LW, Li BD and Chu QD. Elevated chemokine receptor CXCR4 expression in primary tumors following neoadjuvant chemotherapy predicts poor outcomes for patients with locally advanced breast cancer (LABC). Breast Cancer Res Treat. 2009; 113(2):293-299.

26. Hassan S, Ferrario C, Saragovi U, Quenneville L, Gaboury L, Baccarelli A, Salvucci O and Basik M. The influence of tumor-host interactions in the stromal cell-derived factor-1/ CXCR4 ligand/receptor axis in determining metastatic risk in breast cancer. Am J Pathol. 2009; 175(1):66-73.

27. Mizell J, Smith M, Li BD, Ampil F and Chu QD. Overexpression of CXCR4 in primary tumor of patients with HER-2 negative breast cancer was predictive of a poor disease-free survival: a validation study. Ann Surg Oncol. 2009; 16(10):2711-2716.

28. Liu Y, Ji R, Li J, Gu Q, Zhao X, Sun T, Wang J, Du Q and Sun B. Correlation effect of EGFR and CXCR4 and CCR7 chemokine receptors in predicting breast cancer metastasis and prognosis. J Exp Clin Cancer Res. 2010; 29:16.

29. Cabioglu N, Gong Y, Islam R, Broglio KR, Sneige N, Sahin A, Gonzalez-Angulo AM, Morandi P, Bucana C, Hortobagyi GN and Cristofanilli M. Expression of growth factor and chemokine receptors: new insights in the biology of inflammatory breast cancer. Ann Oncol. 2007; 18(6):1021-1029.

30. Chen HW, Du CW, Wei XL, Khoo US and Zhang GJ. Cytoplasmic CXCR4 high-expression exhibits distinct poor clinicopathological characteristics and predicts poor prognosis in triple-negative breast cancer. Curr Mol Med. 2013; 13(3):410-416.

31. Chen SF, Du CW, Yang P, Zhang HW, Kwan M and Zhang GJ. The molecular and clinicopathologic characteristics of bilateral breast cancer. Sci Rep. 2013; 3:2590.

32. Hiller DJ, Meschonat C, Kim R, Li BD and Chu QD. Chemokine receptor CXCR4 level in primary tumors independently predicts outcome for patients with locally advanced breast cancer. Surgery. 2011; 150(3):459-465.

33. Parker CC, Kim RH, Li BD and Chu QD. The chemokine receptor CXCR4 as a novel independent prognostic marker for node-positive breast cancer patients. J Surg Oncol. 2012; 106(4):393-398.

34. Yu S, Wang X, Liu G, Zhu X and Chen Y. High level of CXCR4 in triple-negative breast cancer specimens associated with a poor clinical outcome. Acta Med Okayama. 2013; 67(6):369-375. 
35. D'Alterio C, Avallone A, Tatangelo F, Delrio P, Pecori B, Cella L, Pelella A, D'Armiento FP, Carlomagno C, Bianco F, Silvestro L, Pacelli R, Napolitano M, Iaffaioli $\mathrm{RV}$ and Scala S. A prognostic model comprising pT stage, $\mathrm{N}$ status, and the chemokine receptors CXCR4 and CXCR7 powerfully predicts outcome in neoadjuvant resistant rectal cancer patients. International journal of cancer Journal international du cancer. 2014; 135(2):379-390.

36. Kim J, Takeuchi H, Lam ST, Turner RR, Wang HJ, Kuo C, Foshag L, Bilchik AJ and Hoon DS. Chemokine receptor CXCR4 expression in colorectal cancer patients increases the risk for recurrence and for poor survival. Journal of clinical oncology : official journal of the American Society of Clinical Oncology. 2005; 23(12):2744-2753.

37. Liu Y, Zhou Y, Feng X, Yang P, Yang J, An P, Wang $\mathrm{H}, \mathrm{Ye} \mathrm{S}, \mathrm{Yu} \mathrm{C}, \mathrm{He} \mathrm{Y}$ and Luo H. Low expression of microRNA-126 is associated with poor prognosis in colorectal cancer. Genes Chromosomes Cancer. 2014; 53(4):358-365.

38. Ottaiano A, Franco R, Aiello Talamanca A, Liguori G, Tatangelo F, Delrio P, Nasti G, Barletta E, Facchini G, Daniele B, Di Blasi A, Napolitano M, Ierano C, Calemma $\mathrm{R}$, Leonardi E, Albino V, et al. Overexpression of both $\mathrm{CXC}$ chemokine receptor 4 and vascular endothelial growth factor proteins predicts early distant relapse in stage II-III colorectal cancer patients. Clinical cancer research : an official journal of the American Association for Cancer Research. 2006; 12(9):2795-2803.

39. Saigusa S, Toiyama Y, Tanaka K, Yokoe T, Okugawa Y, Kawamoto A, Yasuda H, Inoue Y, Miki C and Kusunoki M. Stromal CXCR4 and CXCL12 expression is associated with distant recurrence and poor prognosis in rectal cancer after chemoradiotherapy. Ann Surg Oncol. 2010; 17(8):20512058 .

40. Speetjens FM, Liefers GJ, Korbee CJ, Mesker WE, van de Velde CJ, van Vlierberghe RL, Morreau H, Tollenaar RA and Kuppen PJ. Nuclear localization of CXCR4 determines prognosis for colorectal cancer patients. Cancer Microenviron. 2009; 2(1):1-7.

41. Zhang NH, Li J, Li Y, Zhang XT, Liao WT, Zhang JY, Li R and Luo RC. Co-expression of CXCR4 and CD133 proteins is associated with poor prognosis in stage II-III colon cancer patients. Exp Ther Med. 2012; 3(6):973-982.

42. Gockel I, Schimanski CC, Heinrich C, Wehler T, Frerichs K, Drescher D, von Langsdorff C, Domeyer M, Biesterfeld $\mathrm{S}$, Galle PR, Junginger T and Moehler M. Expression of chemokine receptor CXCR4 in esophageal squamous cell and adenocarcinoma. BMC Cancer. 2006; 6:290.

43. Kaifi JT, Yekebas EF, Schurr P, Obonyo D, Wachowiak R, Busch P, Heinecke A, Pantel K and Izbicki JR. Tumorcell homing to lymph nodes and bone marrow and CXCR4 expression in esophageal cancer. J Natl Cancer Inst. 2005; 97(24):1840-1847.

44. Koishi K, Yoshikawa R, Tsujimura T, Hashimoto-Tamaoki $\mathrm{T}$, Kojima S, Yanagi H, Yamamura $\mathrm{T}$ and Fujiwara
Y. Persistent CXCR4 expression after preoperative chemoradiotherapy predicts early recurrence and poor prognosis in esophageal cancer. World journal of gastroenterology : WJG. 2006; 12(47):7585-7590.

45. Lu CL, Ji Y, Ge D, Guo J and Ding JY. The expression of CXCR4 and its relationship with matrix metalloproteinase-9/vascular endothelial growth factor in esophageal squamous cell cancer. Dis Esophagus. 2011; 24(4):283-290.

46. Lu CL, Guo J, Gu J, Ge D, Hou YY, Lin ZW and Ding JY. CXCR4 heterogeneous expression in esophageal squamous cell cancer and stronger metastatic potential with CXCR4positive cancer cells. Dis Esophagus. 2014; 27(3):294-302.

47. Sasaki K, Natsugoe S, Ishigami S, Matsumoto M, Okumura H, Setoyama T, Uchikado Y, Kita Y, Tamotsu K, Hanazono K, Owaki T and Aikou T. Expression of CXCL12 and its receptor CXCR4 in esophageal squamous cell carcinoma. Oncology reports. 2009; 21(1):65-71.

48. Zhang L, Ye SB, Ma G, Tang XF, Chen SP, He J, Liu WL, Xie D, Zeng YX and Li J. The expressions of MIF and CXCR4 protein in tumor microenvironment are adverse prognostic factors in patients with esophageal squamous cell carcinoma. J Transl Med. 2013; 11:60.

49. Fanelli MF, Chinen LT, Begnami MD, Costa WL, Jr., Fregnami JH, Soares FA and Montagnini AL. The influence of transforming growth factor-alpha, cyclooxygenase-2, matrix metalloproteinase (MMP)-7, MMP-9 and CXCR4 proteins involved in epithelial-mesenchymal transition on overall survival of patients with gastric cancer. Histopathology. 2012; 61(2):153-161.

50. He H, Wang C, Shen Z, Fang Y, Wang X, Chen W, Liu F, Qin X and Sun Y. Upregulated expression of C-X-C chemokine receptor 4 is an independent prognostic predictor for patients with gastric cancer. PloS one. 2013; 8(8):e71864.

51. Kwak MK, Hur K, Park DJ, Lee HJ, Lee HS, Kim WH, Lee KU, Choe KJ and Yang HK. Expression of chemokine receptors in human gastric cancer. Tumour Biol. 2005; 26(2):65-70.

52. Lee HJ, Kim SW, Kim HY, Li S, Yun HJ, Song KS, Kim $\mathrm{S}$ and Jo DY. Chemokine receptor CXCR4 expression, function, and clinical implications in gastric cancer. International journal of oncology. 2009; 34(2):473-480.

53. Ying J, Xu Q, Zhang G, Liu B and Zhu L. The expression of CXCL12 and CXCR4 in gastric cancer and their correlation to lymph node metastasis. Med Oncol. 2012; 29(3):17161722.

54. Albert S, Hourseau M, Halimi C, Serova M, Descatoire V, Barry B, Couvelard A, Riveiro ME, Tijeras-Raballand A, de Gramont A, Raymond E and Faivre S. Prognostic value of the chemokine receptor CXCR4 and epithelialto-mesenchymal transition in patients with squamous cell carcinoma of the mobile tongue. Oral Oncol. 2012; 48(12):1263-1271. 
55. Almofti A, Uchida D, Begum NM, Tomizuka Y, Iga H, Yoshida $\mathrm{H}$ and Sato M. The clinicopathological significance of the expression of CXCR4 protein in oral squamous cell carcinoma. International journal of oncology. 2004; 25(1):65-71.

56. Clatot F, Picquenot JM, Choussy O, Gouerant S, Moldovan C, Schultheis D, Cornic M, Francois A, Blot E and LabergeLe-Couteulx S. Intratumoural level of SDF-1 correlates with survival in head and neck squamous cell carcinoma. Oral Oncol. 2011; 47(11):1062-1068.

57. Katayama A, Ogino T, Bandoh N, Nonaka S and Harabuchi Y. Expression of CXCR4 and its down-regulation by IFNgamma in head and neck squamous cell carcinoma. Clinical cancer research : an official journal of the American Association for Cancer Research. 2005; 11(8):2937-2946.

58. Lee JI, Jin BH, Kim MA, Yoon HJ, Hong SP and Hong SD. Prognostic significance of CXCR-4 expression in oral squamous cell carcinoma. Oral Surg Oral Med Oral Pathol Oral Radiol Endod. 2009; 107(5):678-684.

59. Segawa Y, Oda Y, Yamamoto H, Shiratsuchi H, Hirakawa N, Komune S and Tsuneyoshi M. Close correlation between CXCR4 and VEGF expression and their prognostic implications in nasopharyngeal carcinoma. Oncology reports. 2009; 21(5):1197-1202.

60. Wang N, Wu QL, Fang Y, Mai HQ, Zeng MS, Shen GP, Hou JH and Zeng YX. Expression of chemokine receptor CXCR4 in nasopharyngeal carcinoma: pattern of expression and correlation with clinical outcome. J Transl Med. 2005; $3: 26$.

61. Chen D, Gassenmaier M, Maruschke M, Riesenberg R, Pohla H, Stief CG, Zimmermann W and Buchner A. Expression and prognostic significance of a comprehensive epithelial-mesenchymal transition gene set in renal cell carcinoma. J Urol. 2014; 191(2):479-486.

62. An H, Xu L, Zhu Y, Lv T, Liu W, Liu Y, Liu H, Chen L, Xu $\mathrm{J}$ and Lin Z. High CXC chemokine receptor 4 expression is an adverse prognostic factor in patients with clear-cell renal cell carcinoma. British journal of cancer. 2014; 110(9):2261-2268.

63. D'Alterio C, Consales C, Polimeno M, Franco R, Cindolo L, Portella L, Cioffi M, Calemma R, Marra L, Claudio L, Perdona S, Pignata S, Facchini G, Carteni G, Longo N, Pucci L, et al. Concomitant CXCR4 and CXCR7 expression predicts poor prognosis in renal cancer. Curr Cancer Drug Targets. 2010; 10(7):772-781.

64. Li X, Huang Y, Xia J, Chen N, Wei Q, Zhang P, Shen $\mathrm{PF}$, Wang $\mathrm{J}$ and Zeng $\mathrm{H}$. CXCR4 expression in patients with high-risk locally advanced renal cell carcinoma can independently predict increased risk of disease progression and poor overall survival. Asian Pacific journal of cancer prevention : APJCP. 2011; 12(12):3313-3318.

65. Li G, Badin G, Zhao A, Gentil-Perret A, Tostain J, Peoc'h $\mathrm{M}$ and Gigante M. Prognostic value of CXCR4 expression in patients with clear cell renal cell carcinoma. Histol Histopathol. 2013; 28(9):1217-1222.
66. Wang L, Chen W, Gao L, Yang Q, Liu B, Wu Z, Wang Y and Sun Y. High expression of CXCR4, CXCR7 and SDF1 predicts poor survival in renal cell carcinoma. World journal of surgical oncology. 2012; 10:212.

67. Otsuka S, Klimowicz AC, Kopciuk K, Petrillo SK, Konno M, Hao D, Muzik H, Stolte E, Boland W, Morris D, Magliocco AM and Bebb DG. CXCR4 overexpression is associated with poor outcome in females diagnosed with stage IV non-small cell lung cancer. Journal of thoracic oncology : official publication of the International Association for the Study of Lung Cancer. 2011; 6(7):11691178.

68. Reckamp KL, Figlin RA, Burdick MD, Dubinett SM, Elashoff RM and Strieter RM. CXCR4 expression on circulating pan-cytokeratin positive cells is associated with survival in patients with advanced non-small cell lung cancer. BMC Cancer. 2009; 9:213.

69. Spano JP, Andre F, Morat L, Sabatier L, Besse B, Combadiere C, Deterre P, Martin A, Azorin J, Valeyre D, Khayat D, Le Chevalier T and Soria JC. Chemokine receptor CXCR4 and early-stage non-small cell lung cancer: pattern of expression and correlation with outcome. Ann Oncol. 2004; 15(4):613-617.

70. Wagner PL, Hyjek E, Vazquez MF, Meherally D, Liu YF, Chadwick PA, Rengifo T, Sica GL, Port JL, Lee PC, Paul S, Altorki NK and Saqi A. CXCL12 and CXCR4 in adenocarcinoma of the lung: association with metastasis and survival. J Thorac Cardiovasc Surg. 2009; 137(3):615621.

71. Wang M, Chen GY, Song HT, Hong X, Yang ZY and Sui GJ. Significance of CXCR4, phosphorylated STAT3 and VEGF-A expression in resected non-small cell lung cancer. Exp Ther Med. 2011; 2(3):517-522.

72. Al Zobair AA, Al Obeidy BF, Yang L, Yang C, Hui Y, $\mathrm{Yu} \mathrm{H}$, Zheng F, Yang G, Xie C, Zhou F and Zhou Y. Concomitant overexpression of EGFR and CXCR4 is associated with worse prognosis in a new molecular subtype of non-small cell lung cancer. Oncology reports. 2013; 29(4):1524-1532.

73. Franco R, Cantile M, Scala S, Catalano E, Cerrone M, Scognamiglio G, Pinto A, Chiofalo MG, Caraco C, Anniciello AM, Abbruzzese A, Caraglia M and Botti G. Histomorphologic parameters and CXCR4 mRNA and protein expression in sentinel node melanoma metastasis are correlated to clinical outcome. Cancer biology \& therapy. 2010; 9(6):423-429.

74. Longo-Imedio MI, Longo N, Trevino I, Lazaro P and Sanchez-Mateos P. Clinical significance of CXCR3 and CXCR4 expression in primary melanoma. International journal of cancer Journal international du cancer. 2005; 117(5):861-865.

75. Scala S, Ottaiano A, Ascierto PA, Cavalli M, Simeone E, Giuliano P, Napolitano M, Franco R, Botti G and Castello G. Expression of CXCR4 predicts poor prognosis in patients with malignant melanoma. Clinical cancer research 
: an official journal of the American Association for Cancer Research. 2005; 11(5):1835-1841.

76. Scala S, Ierano C, Ottaiano A, Franco R, La Mura A, Liguori G, Mascolo M, Staibano S, Ascierto PA, Botti G, De Rosa $\mathrm{G}$ and Castello G. CXC chemokine receptor 4 is expressed in uveal malignant melanoma and correlates with the epithelioid-mixed cell type. Cancer Immunol Immunother. 2007; 56(10):1589-1595.

77. Jiang YP, Wu XH, Shi B, Wu WX and Yin GR. Expression of chemokine CXCL12 and its receptor CXCR4 in human epithelial ovarian cancer: an independent prognostic factor for tumor progression. Gynecol Oncol. 2006; 103(1):226233.

78. Kodama J, Hasengaowa, Kusumoto T, Seki N, Matsuo T, Ojima Y, Nakamura K, Hongo A and Hiramatsu Y. Association of CXCR4 and CCR7 chemokine receptor expression and lymph node metastasis in human cervical cancer. Ann Oncol. 2007; 18(1):70-76.

79. Li J, Jiang K, Qiu X, Li M, Hao Q, Wei L, Zhang W, Chen $\mathrm{B}$ and Xin X. Overexpression of CXCR4 is significantly associated with cisplatin-based chemotherapy resistance and can be a prognostic factor in epithelial ovarian cancer. BMB Rep. 2014; 47(1):33-38.

80. Oda Y, Ohishi Y, Basaki Y, Kobayashi H, Hirakawa T, Wake N, Ono M, Nishio K, Kuwano M and Tsuneyoshi M. Prognostic implications of the nuclear localization of Y-box-binding protein-1 and CXCR4 expression in ovarian cancer: their correlation with activated Akt, LRP/MVP and P-glycoprotein expression. Cancer science. 2007; 98(7):1020-1026.

81. Pils D, Pinter A, Reibenwein J, Alfanz A, Horak P, Schmid BC, Hefler L, Horvat R, Reinthaller A, Zeillinger R and Krainer M. In ovarian cancer the prognostic influence of HER2/neu is not dependent on the CXCR4/SDF1 signalling pathway. British journal of cancer. 2007; 96(3):485-491.

82. Sekiya R, Kajiyama H, Sakai K, Umezu T, Mizuno M, Shibata K, Yamamoto E, Fujiwara S, Nagasaka T and Kikkawa F. Expression of CXCR4 indicates poor prognosis in patients with clear cell carcinoma of the ovary. Hum Pathol. 2012; 43(6):904-910.

83. Shiozaki T, Tabata T, Ma N, Yamawaki T, Motohashi T, Kondo E, Tanida K, Okugawa T and Ikeda T. Association of $\mathrm{CXC}$ chemokine receptor type 4 expression and clinicopathologic features in human vulvar cancer. Int $\mathrm{J}$ Gynecol Cancer. 2013; 23(6):1111-1117.

84. Gebauer F, Tachezy M, Effenberger K, von Loga K, Zander H, Marx A, Kaifi JT, Sauter G, Izbicki JR and Bockhorn M. Prognostic impact of CXCR4 and CXCR7 expression in pancreatic adenocarcinoma. J Surg Oncol. 2011; 104(2):140-145.

85. Marechal R, Demetter P, Nagy N, Berton A, Decaestecker C, Polus M, Closset J, Deviere J, Salmon I and Van Laethem JL. High expression of CXCR4 may predict poor survival in resected pancreatic adenocarcinoma. British journal of cancer. 2009; 100(9):1444-1451.

86. Akashi T, Koizumi K, Tsuneyama K, Saiki I, Takano Y and Fuse H. Chemokine receptor CXCR4 expression and prognosis in patients with metastatic prostate cancer. Cancer science. 2008; 99(3):539-542.

87. Jung SJ, Kim CI, Park CH, Chang HS, Kim BH, Choi MS and Jung HR. Correlation between Chemokine Receptor CXCR4 Expression and Prognostic Factors in Patients with Prostate Cancer. Korean J Urol. 2011; 52(9):607-611.

88. Xiang ZL, Zeng ZC, Tang ZY, Fan J, Zhuang PY, Liang Y, Tan YS and He J. Chemokine receptor CXCR4 expression in hepatocellular carcinoma patients increases the risk of bone metastases and poor survival. BMC Cancer. 2009; 9:176.

89. Yopp AC, Shia J, Butte JM, Allen PJ, Fong Y, Jarnagin WR, DeMatteo RP and D'Angelica MI. CXCR4 expression predicts patient outcome and recurrence patterns after hepatic resection for colorectal liver metastases. Ann Surg Oncol. 2012; 19 Suppl 3:S339-346.

90. Lin F, Zheng SE, Shen Z, Tang LN, Chen P, Sun YJ, Zhao $\mathrm{H}$ and Yao Y. Relationships between levels of CXCR4 and VEGF and blood-borne metastasis and survival in patients with osteosarcoma. Med Oncol. 2011; 28(2):649-653.

91. Oda Y, Tateishi N, Matono H, Matsuura S, Yamamaoto H, Tamiya S, Yokoyama R, Matsuda S, Iwamoto Y and Tsuneyoshi M. Chemokine receptor CXCR4 expression is correlated with VEGF expression and poor survival in soft-tissue sarcoma. International journal of cancer Journal international du cancer. 2009; 124(8):1852-1859.

92. Yao X, Zhou L, Han S and Chen Y. High expression of CXCR4 and CXCR7 predicts poor survival in gallbladder cancer. J Int Med Res. 2011; 39(4):1253-1264.

93. Domanska UM, Kruizinga RC, Nagengast WB, TimmerBosscha H, Huls G, de Vries EG and Walenkamp AM. A review on CXCR4/CXCL12 axis in oncology: no place to hide. Eur J Cancer. 2013; 49(1):219-230.

94. Kaplan RN, Riba RD, Zacharoulis S, Bramley AH, Vincent L, Costa C, MacDonald DD, Jin DK, Shido K, Kerns SA, Zhu Z, Hicklin D, Wu Y, Port JL, Altorki N, Port ER, et al. VEGFR1-positive haematopoietic bone marrow progenitors initiate the pre-metastatic niche. Nature. 2005; 438(7069):820-827.

95. Wong D and Korz W. Translating an Antagonist of Chemokine Receptor CXCR4: from bench to bedside. Clinical cancer research : an official journal of the American Association for Cancer Research. 2008; 14(24):7975-7980.

96. Liberati A, Altman DG, Tetzlaff J, Mulrow C, Gotzsche PC, Ioannidis JP, Clarke M, Devereaux PJ, Kleijnen J and Moher D. The PRISMA statement for reporting systematic reviews and meta-analyses of studies that evaluate health care interventions: explanation and elaboration. PLoS Med. 2009; 6(7):e1000100.

97. Tierney JF, Stewart LA, Ghersi D, Burdett S and Sydes MR. Practical methods for incorporating summary time-to- 
event data into meta-analysis. Trials. 2007; 8:16.

98. Wu J, Wu X, Liang W, Chen $\mathrm{C}$, Zheng $\mathrm{L}$ and An H. Clinicopathological and prognostic significance of chemokine receptor CXCR4 overexpression in patients with esophageal cancer: a meta-analysis. Tumour Biol. 2014; 35(4):3709-3715.

99. Liu CF, Liu SY, Min XY, Ji YY, Wang N, Liu D, Ma N, $\mathrm{Li} \mathrm{ZF}$ and $\mathrm{Li} \mathrm{K}$. The prognostic value of CXCR4 in ovarian cancer: a meta-analysis. PloS one. 2014; 9(3):e92629.

100. Zhang Z, Ni C, Chen W, Wu P, Wang Z, Yin J, Huang J and Qiu F. Expression of CXCR4 and breast cancer prognosis: a systematic review and meta-analysis. BMC Cancer. 2014; 14:49.

101. Stang A. Critical evaluation of the Newcastle-Ottawa scale for the assessment of the quality of nonrandomized studies in meta-analyses. Eur J Epidemiol. 2010; 25(9):603-605.

102. Higgins JP, Thompson SG, Deeks JJ and Altman DG. Measuring inconsistency in meta-analyses. BMJ. 2003; 327(7414):557-560.

103. DerSimonian R and Laird N. Meta-analysis in clinical trials. Control Clin Trials. 1986; 7(3):177-188.

104. Begg CB and Mazumdar M. Operating characteristics of a rank correlation test for publication bias. Biometrics. 1994; 50(4):1088-1101. 